\title{
$\alpha$-Synuclein-Dependent Calcium Entry Underlies Differential Sensitivity of Cultured SN and VTA Dopaminergic Neurons to a Parkinsonian Neurotoxin
}

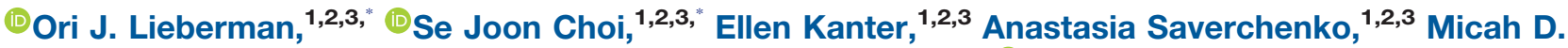 \\ Frier, ${ }^{1,2,3}$ Giulia M. Fiore,, ${ }^{1,2,3}$ Min Wu, ${ }^{1,2,3}$ Jyothisri Kondapalli, ${ }^{5}$ DErico Zampese, ${ }^{5}$ D. James Surmeier, ${ }^{5}$ \\ David Sulzer, ${ }^{1,2,3,4}$ and (D)Eugene V. Mosharov ${ }^{1,2,3}$

\section{DOI:http://dx.doi.org/10.1523/ENEURO.0167-17.2017} \\ ${ }^{1}$ New York State Psychiatric Institute, Columbia University Medical Center, New York, NY 10032, ${ }^{2}$ Department of Psychiatry, \\ Columbia University Medical Center, New York, NY 10032, ${ }^{3}$ Department of Neurology, Columbia University Medical Center, \\ New York, NY 10032, ${ }^{4}$ Department of Pharmacology, Columbia University Medical Center, New York, NY 10032, and \\ ${ }^{5}$ Department of Physiology, Northwestern University Feinberg School of Medicine, Chicago, IL 60611
}

\begin{abstract}
Parkinson's disease (PD) is a debilitating neurodegenerative disease characterized by a loss of dopaminergic neurons in the substantia nigra (SN). Although mitochondrial dysfunction and dysregulated $\alpha$-synuclein (aSyn) expression are postulated to play a role in PD pathogenesis, it is still debated why neurons of the SN are targeted while neighboring dopaminergic neurons of the ventral tegmental area (VTA) are spared. Using electrochemical and imaging approaches, we investigated metabolic changes in cultured primary mouse midbrain dopaminergic neurons exposed to a parkinsonian neurotoxin, 1-methyl-4-phenylpyridinium $\left(\mathrm{MPP}^{+}\right)$. We demonstrate that the higher level of neurotoxicity in $\mathrm{SN}$ than VTA neurons was due to SN neuron-specific toxin-induced increase in cytosolic dopamine (DA) and $\mathrm{Ca}^{2+}$, followed by an elevation of mitochondrial $\mathrm{Ca}^{2+}$, activation of nitric oxide synthase (NOS), and mitochondrial oxidation. The increase in cytosolic $\mathrm{Ca}^{2+}$ was not caused by MPP ${ }^{+}$-induced oxidative stress, but rather depended on the activity of both L-type calcium channels and aSyn expression, suggesting that these two established pathogenic factors in PD act in concert.
\end{abstract}

Key words: $\alpha$-synuclein; calcium; mitochondria; dopamine; Parkinson's disease; neurodegeneration; MPP ${ }^{+}$; MPTP

\section{Significance Statement}

The authors investigated the mechanism of differential sensitivity of substantia nigra (SN) and ventral tegmental area (VTA) dopaminergic neurons to a mitochondrial neurotoxin 1-methyl-4-phenylpyridinium $\left(\mathrm{MPP}^{+}\right.$). They demonstrate that $\alpha$-synuclein (aSyn)- and L-type calcium channel-dependent elevation of calcium is the primary cause of mitochondrial oxidation and toxicity in SN neurons. This finding connects two disparate areas of Parkinson's disease (PD) research and uncovers a novel interaction between the primary genetic risk factor for PD, mitochondrial dysfunction, and calcium signaling.

\section{Introduction}

Parkinson's disease (PD) is a debilitating neurodegenerative disorder defined by bradykinesia, postural insta-

Received May 12, 2017; accepted November 9, 2017; First published November 15, 2017.

The authors declare no competing financial interests. bility, resting tremor, and muscular rigidity. Although significant symptomatic benefits can be provided to patients by treatment with levodopa, no disease modifying 
treatment exists for PD, indicating that a better understanding of underlying pathologic mechanisms is needed to develop improved therapy. Patients with PD demonstrate selective cell death of dopaminergic neurons in the substantia nigra $(\mathrm{SN})$ with relative sparing of neighboring dopamine (DA) neurons of the ventral tegmental area (VTA). Notably, proteinaceous $\alpha$-synuclein (aSyn)-positive deposits, Lewy bodies, are found in the ventral midbrain and other affected brain areas, and mutations or gene multiplication of aSyn cause autosomal dominant PD, suggesting a role for this protein in mediating disease pathology. Finally, mitochondrial dysfunction has also been proposed to underlie DA neurons degeneration as several PD genes encode proteins related to normal mitochondria homeostasis (Ryan et al., 2015). Identifying how aSyn and mitochondrial dysfunction may interact to yield selective cell death represents an attractive approach to understanding PD pathophysiology.

The environmental neurotoxin 1-methyl-4-phenyl-1,2,3,6tetrahydropyridine (MPTP) recapitulates many pathologic features of idiopathic PD (Davis et al., 1979; Langston et al., 1983), including selective degeneration of SN dopaminergic neurons, and the dependence of this toxicity on the expression of endogenous aSyn (Dauer et al., 2002). Understanding how a putative mitochondrial poison could yield selective degeneration of SN but not VTA neurons may uncover novel approaches to develop disease-modifying therapies for PD and related neurodegenerative disorders.

MPTP is metabolized by astroglia to the active toxin, 1-methyl-4-phenylpyridinium (MPP ${ }^{+}$), which accumulates in DA neurons as a substrate for the DA uptake transporter (DAT; Javitch et al., 1985). Hypotheses on how $\mathrm{MPP}^{+}$leads to selective SN neuron death can be subsumed into two categories. First, increased toxicity may result from a higher intracellular concentration of $\mathrm{MPP}^{+}$ achieved inside SN neurons. This has been credited to extraneuronal factors, such as a region-specific expression of the transporters that release $\mathrm{MPP}^{+}$from astroglia (Cui et al., 2009), or increased uptake of the toxin due to higher expression of DAT in SN than VTA neurons (Shimada et al., 1992; Hurd et al., 1994; Sanghera et al., 1997; González-Hernández et al., 2004). Alternatively, SN neu-

O.J.L., S.J.C., A.S., G.M.F., and E.V.M. analyzed data; O.J.L., S.J.C., and E.V.M. wrote the paper.

This work was supported by National Institute of Neurological Disorders and Stroke at the National Institutes of Health Grants NS075222 (to E.V.M.) and NS047085 (to D.J.S.), T32 GM007367 (to O.L.), the Parkinson's Disease Foundation (D.S.), the JPB Foundations (D.S. and D.J.S.)

${ }^{*}$ O.J.L. and S.J.C. contributed equally to this work.

Acknowledgements: We thank Dr. Diego De Stefani (Department of Biomedical Sciences, University of Padova, Italy), for providing the plasmid for $2 \mathrm{mt}-$ GCaMP6m, and Dr. Susan Lindquist and Dr. Gabriela Caraveo (Whitehead Institute for Biomedical Research, Cambridge, MA) for the AAV2-mKate2 virus.

Correspondence should be addressed to Eugene V. Mosharov, Department of Psychiatry, Columbia University, Kolb Building Unit 1, 40 Haven Avenue, New York, NY 10013, E-mail: em706@columbia.edu.

DOI:http://dx.doi.org/10.1523/ENEURO.0167-17.2017

Copyright @ 2017 Lieberman et al.

This is an open-access article distributed under the terms of the Creative Commons Attribution 4.0 International license, which permits unrestricted use, distribution and reproduction in any medium provided that the original work is properly attributed. rons may be more sensitive to $\mathrm{MPP}^{+}$due to intrinsic factors, including higher axonal arborization leading to elevated bioenergetic requirements (Pacelli et al., 2015), higher levels of cytosolic DA (DA ${ }_{\text {cyt }}$; Mosharov et al., 2009), or selective expression of the voltage-gated L-type calcium channel ( $\mathrm{Ca}_{\mathrm{v}} 1.3$; Chan et al., 2007) and GirK2 potassium channels (Chung et al., 2005), activation of K-ATP channels (Liss et al., 2005) or dynamin-like protein 1 (Wang et al., 2011).

Here, we used electrochemical and imaging methods on primary mouse DA neuronal cultures to determine factors underlying the selectivity of cell death following $\mathrm{MPP}^{+}$exposure. We show that, although there is higher DAT activity in SN compared to VTA DA neurons, this cannot fully account for the difference in their susceptibility to $\mathrm{MPP}^{+}$. In contrast, we found that the toxin selectively elevated cytosolic and mitochondrial $\mathrm{Ca}^{2+}$ in $\mathrm{SN}$ neurons, and that blocking this response decreased mitochondrial oxidation and neurotoxicity. The increase in $\mathrm{Ca}^{2+}$ following $\mathrm{MPP}^{+}$exposure was dependent on the activities of L-type $\mathrm{Ca}^{2+}$ channels (LTCCs) and ryanodine receptors (RyRs), and the expression of aSyn. Overall, our data support a role for disrupted $\mathrm{Ca}^{2+}$ homeostasis in PD and other synucleinopathies and suggest that two wellknown players of PD pathogenesis converge on the same neurotoxicity pathway.

\section{Materials and Methods}

\section{Animals and neuronal cultures}

Mice were housed according to the National Institutes of Health guidelines under a 12/12 h light/dark cycle with ad libitum access to food and water. All animal studies were reviewed and approved by the Institutional Animal Care and Use Committee. C57BL/6, DAT ${ }^{\mathrm{IRES}}$ (s)e (strain

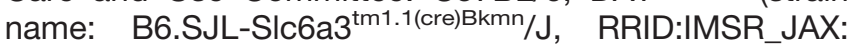
006660) and Ai38 floxed GCaMP3 reporter (strain name:

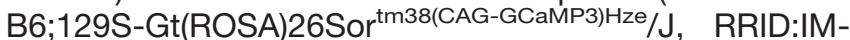
SR_JAX:014538) mouse lines were obtained from The Jackson Laboratory. For measurements of mitochondrial oxidation in combination with $\mathrm{Ca}^{2+}$ and $\mathrm{NO}$ probes, we used cultures from transgenic mice expressing a mitochondrially targeted ratiometric redox probe, roGFP (Dooley et al., 2004) under the control of the TH promoter (TH-mito-roGFP; Guzman et al., 2010). For DA cyt $_{\text {mea- }}$ surements, we used cultures from mice that express green fluorescent protein under the control of the rat tyrosine hydroxylase promoter (TH-GFP; Sawamoto et al., 2001). SN and VTA DA neurons from postnatal day 0-2 mice of either sex were dissected, dissociated, and plated on a monolayer of rat cortical astrocytes at the plating density of $\sim 100,000$ cells $/ \mathrm{cm}^{2}$, as described previously (Rayport et al., 1992); experiments were conducted 10-15 $\mathrm{d}$ after plating.

To overexpress human wild-type (WT) aSyn, we used adeno-associated virus serotype 2 (AAV2)-aSyn under the control of chicken $\beta$-actin (CBA) promoter produced by the UNC Vector Core Facility and available from the Michael J. Fox Foundation (New York, NY). As a control, we employed AAV2-mKate2 (red fluorescence; Shcherbo et al., 2009; Caraveo et al., 2014). The viruses were used 
on cultures from DAT-GCaMP3 animals at a 20,00030,000 genome copies/cell concentration, resulting in $>90 \%$ infection of dopaminergic neurons. GCaMP3 fluorescence measurements were performed 5-7 d postinfection.

\section{Neurotoxicity assays}

Cells were preincubated with various metabolic effectors for the time indicated in the text before the application of either $\mathrm{MPP}^{+}$or pierecidin A (Sigma). After $48 \mathrm{~h}$, immunostaining of $4 \%$ paraformaldehyde-fixed cultures was performed using mouse anti-TH antibodies (1:1000; Millipore Bioscience Research Reagents; RRID: AB_2201526) followed by secondary antibodies conjugated with Alexa Fluor 488 (1:300; Invitrogen; RRID: AB_141607). For each dish the number of immunereactive cells in 20 fields of view at $200 \times$ magnification (Plan-Neofluar 20× objective; $\sim 0.8 \mathrm{~mm}^{2}$ viewing field) was tallied and the average density was calculated (Mosharov et al., 2009). The counts were performed by an observer blind to the experimental treatments; each experimental condition was repeated at least twice with at least three dishes per condition in each of the experiments.

\section{Electrophysiological recordings}

For whole-cell patch-clamp recording from cultured VTA and SN DA neurons, cells were kept at room temperature in Tyrode's solution containing $119 \mathrm{mM} \mathrm{NaCl}, 3$ $\mathrm{mM} \mathrm{KCl}, 10 \mathrm{mM}$ glucose, $2 \mathrm{mM} \mathrm{CaCl}_{2}, 1.2 \mathrm{mM} \mathrm{MgCl}_{2}-6$ $\mathrm{mM} \mathrm{H}_{2} \mathrm{O}$, 3.3 mM HEPES, and $2.7 \mathrm{mM}$ HEPES-Na ${ }^{+}$salt; $\mathrm{pH}$ 7.2-7.4, $270 \mathrm{mOsm}$. Borosilicate glass pipettes with a tip resistance of 3-4 M $\Omega$ (G150F-4; Warner Instruments) were pulled on a P-97 Flaming-Brown micropipette puller (Sutter Instruments) and filled with $115 \mathrm{mM} \mathrm{K}$-gluconate, $20 \mathrm{mM} \mathrm{KCl}, 10 \mathrm{mM}$ HEPES, $2 \mathrm{mM} \mathrm{MgCl}_{2}$, 2 mM ATP-Mg, $2 \mathrm{mM}$ ATP-Na , and $0.3 \mathrm{mM}$ GTP-Na; pH 7.25, 280 mOsm. Neurons were visualized under a $40 \times$ water immersion objective by fluorescence and DIC optics (BX51; Olympus). Whole-cell current clamp recording were performed with an Axopatch 700B amplifier (Molecular Devices) and digitized at $10 \mathrm{kHz}$ with ITC-18 (HEKA Instruments). Data were acquired using WinWCP software (written by John Dempster, University of Strathclyde, United Kingdom). Spontaneous firing frequency was measured in cell-attached mode, then cell membrane was ruptured and holding potential adjusted to $-60 \mathrm{mV}$. In each cell, membrane capacitance, input resistance and evoked action potentials were measured by injecting somatic currents from 0 to $+190 \mathrm{pA}$ in +10 -pA increments for $1 \mathrm{~s}$. Tetrodotoxin (TTX; $0.5 \mu \mathrm{M}$ ) was perfused to measure resting membrane potential and current-voltage relationship (-300 to $+300 \mathrm{pA},+100-\mathrm{pA}$ increments for $1 \mathrm{~s})$. Data analysis and statistics were performed using Clampfit (Molecular Devices) and GraphPad Prism (GraphPad software). Data are presented as mean \pm SEM with statistical analysis run by Mann-Whitney $t$ test and two-way ANOVA.

\section{Measurements of $\mathrm{DA}_{\text {cyt }}$ by intracellular patch electrochemistry (IPE)}

Measurements of neuronal $\mathrm{DA}_{\text {cyt }}$ in cultures from $\mathrm{TH}-$ GFP mice were performed as described previously
(Mosharov et al., 2009). Briefly, we used an IPE electrode holder that allowed to house a polyethylene-coated 5- $\mu \mathrm{m}$ carbon fiber electrode (CFE) inside the glass patch pipette. Voltage ramps from $-450 \mathrm{mV}$ holding potential to $+800 \mathrm{mV}$ over $8.5 \mathrm{~ms}$ (scan rate of $295 \mathrm{mV} / \mathrm{ms}$ ) were applied to the CFE at $100 \mathrm{~ms}$ intervals using a subroutine locally written in IGOR Pro (WaveMetrics). Subtraction voltammograms were generated, and DA concentration at the maximum of the oxidation wave was calculated using calibration curves generated for CFEs with different detection surface areas (Mosharov et al., 2003). The initial DA concentration in cellular cytosol was calculated using the cell body volume and the volume of the pipette tip estimated from photographs taken before each recording. All drugs and inhibitors were present in the bath and in the patch pipette. Because the concentration of $D A_{c y t}$ is below the detection limits in untreated DA neurons, cultures were preincubated for $30 \mathrm{~min}$ with $100 \mu \mathrm{M}$ L-DOPA. The drug was also present in the bath and in the patch pipette during the recordings, which increased the baseline oxidation current but did not otherwise interfere with DA measurements. Within each experiment, the same CFE was used for measurements from experimental and control groups of cells. IPE measurements were performed at room temperature.

\section{DAT activity}

To estimate DAT activity, we employed 4-(4-dimethylamino)phenyl-1-methylpyridinium $\left(\mathrm{APP}^{+}\right)$, a fluorescent analog of $\mathrm{MPP}^{+}$and a DAT substrate (Karpowicz et al., 2013). Cells from WT mice were incubated with indicated concentrations of $\mathrm{APP}^{+}$for $10 \mathrm{~min}$, rinsed twice and imaged using $410 \mathrm{~nm}$ excitation and $535 \mathrm{~nm}$ emission filters.

As an independent approach to measure DATmediated uptake, SN and VTA neuronal cultures were preincubated with $10 \mu \mathrm{M}$ pargyline and $2 \mu \mathrm{M}$ reserpine for $30 \mathrm{~min}$ and then with $10 \mu \mathrm{M}$ DA for $60 \mathrm{~min}$ at $37^{\circ} \mathrm{C}$. Extracellular DA was then rinsed and $\mathrm{DA}_{\text {cyt }}$ measured by IPE as above. DAT-specific transport was derived as a difference between $\mathrm{DA}_{\mathrm{cyt}}$ concentrations in the presence and in the absence of $10 \mu \mathrm{M}$ nomifensine (added $30 \mathrm{~min}$ before DA). HPLC measurements performed under the same experimental conditions showed that cellular DA is stably elevated for at least 30 min after the external DA washout (data not shown).

\section{Fluorescent microscopy}

For live cell imaging, cultures were mounted on an open perfusion chamber and superfused with recording saline $\left(0.5 \mathrm{ml} / \mathrm{min}\right.$ at $\left.\sim 30^{\circ} \mathrm{C}\right)$. Cultures were imaged with an Olympus IX81 inverted fluorescence microscope equipped with a digitized stage (ProScan; Prior Scientific), a $63 \times /$ 1.35 oil objective (Olympus), a corresponding fluorescence filter set and a 2.0 neutral density filter using a CoolSNAP HQ camera (Roper Scientific/Photometrics) and MetaMorph software (Molecular Devices). For each fluorescent reporter, 10-50 images or pairs of images were acquired at 200-ms exposure time at a frequency of 1-2 Hz. Analysis was performed with ImageJ software (NIH). Images were background corrected frame by frame 
by subtracting out the mean pixel values of a cell-free region or underlying glial cells depending on the location of the cell. For each time frame, fluorescence intensity was represented by the mean of averaged pixel intensities in three regions of neuronal soma, excluding the nucleus. The average of a time series represented neuron fluorescence used for statistical analysis.

For immunofluorescence, paraformaldehyde-fixed cultures were labeled at $4^{\circ} \mathrm{C}$ overnight with mouse anti-TH antibodies (1:1000; Millipore Bioscience Research Reagents; RRID: AB_2201526), rabbit anti ATF6 (1:500; ab37149 from ABCAM; RRID: AB_725571), or aSyn (1: 100; clone 42, BD Biosciences; RRID: AB_398107), followed by Alexa Fluor fluorescent secondary antibodies (1:300; Invitrogen). Cells were imaged using $63 \times / 1.35$ oil objective (Olympus), a corresponding fluorescence filter set and a 2.0 neutral density filter using an Orca Flash 4 V3 camera (Hamamatsu) and MetaMorph software (Molecular Devices; RRID: SCR_002368). aSyn immunofluorescence was determined in the cell soma, excluding the nucleus. For the quantification of ATF6 intracellular distribution, the ratio of fluorescence intensities inside the nucleus and in the perinuclear region of the cytosol was calculated for each cell.

\section{Mitochondrial oxidation}

For each cell from TH-mito-roGFP mice, 10 series of pairs of fluorescent images at 410 and $470 \mathrm{~nm}$ excitation and $535 \mathrm{~nm}$ emission were taken (Chroma Technology, filter set 71012). At the end of each experiments, the maximal and minimal fluorescence of roGFP was determined by a 15-min application of $2 \mathrm{mM}$ dithiothreitol (DTT) to fully reduce the probe, and then $2 \mathrm{mM}$ hydrogen peroxide $\left(\mathrm{H}_{2} \mathrm{O}_{2}\right)$ to fully oxidize it. Relative oxidation of the mitochondria was calculated as previously described (Guzman et al., 2010) as $\left.1-\left(\left(\mathrm{F}-\mathrm{F}_{\mathrm{H} 2 \mathrm{O} 2}\right) / \mathrm{F}_{\mathrm{DTT}}-\mathrm{F}_{\mathrm{H} 2 \mathrm{O} 2}\right)\right)$.

\section{Mitochondria morphology}

Mitochondria morphology was analyzed as described previously (Dagda et al., 2009) using ImageJ. Briefly, epifluorescent images of TH-mito-roGFP signal were median filtered and loaded into the mitochondrial morphology plugin to obtain mitochondrial circularity data. For morphology comparisons between aSyn knock-out and WT neurons, cells were incubated with $1 \mu \mathrm{M}$ mitotracker Red for $1 \mathrm{~h}$ followed by a 30-min wash in Tyrode's saline and imaged using $560 \mathrm{~nm}$ excitation and $630 \mathrm{~nm}$ emission (Chroma Technology, filter set 49008). Epifluorescent microscope images were median filtered and the Feret diameter of mitotracker-labeled puncta were manually determined for each cell by an observer blind to genotype and treatment condition. DA neurons were identified by labeling with $\mathrm{APP}^{+}$.

\section{Mitochondrial $\mathrm{Ca}^{2+}$}

Adeno-associated virus that expresses mitochondrial GCaMP6m $\left(K_{\mathrm{d}}=167 \mathrm{nM} \mathrm{Ca}^{2+}\right)$ under the control of rat TH promoter was developed as follows. The plasmid for the mitochondrial matrix targeted $\mathrm{Ca}^{2+}$ sensor GCaMP6m (Logan et al., 2014; Patron et al., 2014) was a generous gift from Dr. Diego De Stefani (Department of Biomedical
Sciences, University of Padova, Italy). A 1558-bp 2mtGCaMP6m insert was PCR amplified using forward (AACTTAAGCTTGGTACCGAGCTCGGATCCATG) and reverse (GAATTCTCACTTCGCTGTCATCATTTGTACAAAC) primers. The PCR fragment was subcloned into EcoR1 site of pAAV-TH-Sv40 poly A vector. The final construct was packaged into AAV serotype 9 (AAV9) by Virovek.

WT midbrain cultures (14 days in vitro) were treated with the AAV9 TH-2mt-GCaMP6m viral stock $\left(2.41^{+13}\right.$ viral particles $/ \mathrm{ml}$ ) as follows. All media, except $\sim 100 \mu \mathrm{l}$, were removed, $0.5 \mu \mathrm{l}$ of the stock added overnight, and 2 $\mathrm{ml}$ of fresh media added the next day. Cells were used 4-5 d postinfection. Poststaining of midbrain cultures infected with the virus showed that $>85 \%$ of $2 \mathrm{mt}-\mathrm{GCaMP} 6 \mathrm{~m}$ positive neurons were TH-positive (41 of 47 cells). Cells expressing $2 \mathrm{mt}-\mathrm{GCaMP} 6 \mathrm{~m}$ were imaged at 410 and 470 $\mathrm{nm}$ excitation and $535 \mathrm{~nm}$ emission (Chroma Technology, filter set 71012). As exciting GCaMP6m at $410 \mathrm{~nm}$ isosbestic point led to fluorescence emission that was not $\mathrm{Ca}^{2+}$ dependent (Logan et al., 2014), the ratio between the excitation wavelengths of 470 and $410 \mathrm{~nm}$ was proportional to the $\mathrm{Ca}^{2+}$ concentration and independent of probe expression levels.

\section{Intracellular $\mathrm{Ca}^{2+}$}

For measurements using Rhod2-AM (Invitrogen), fura-2 AM (Invitrogen), or Calcein Blue-AM (Invitrogen), we used cultures from TH-GFP and TH-mito-roGFP mice for the identification of DA neurons. Stock solution of an AM ester (1-5 $\mu \mathrm{l} ; 1 \mu \mathrm{g} / \mathrm{ml}$ DMSO) was mixed with $1 \mu \mathrm{l}$ of pluronic-F-127 solution (20\% in DMSO; Invitrogen), sonicated briefly and added to the culture dish containing 2 $\mathrm{ml}$ of medium. While Rhod2-AM can be chemically reduced to its protonated form that should preferentially accumulate in mitochondria (Hajnóczky et al., 1995), this procedure employs a strong reducing agent, sodium borohydride $\left(\mathrm{NaBH}_{4}\right)$, that can interfere with the effects of $\mathrm{MPP}^{+}$. We therefore used a regular, non-reduced form of Rhod2-AM that resulted in a mostly cytosolic and nuclear staining of DA neurons.

After rinsing the cells twice with recording saline, dishes were mounted in the perfusion chamber and imaged 30 min later at $\sim 30^{\circ} \mathrm{C}$. Fura-2 was imaged using a filter wheel (Prior Scientific), switching between 340 and $380 \mathrm{~nm}$ excitation filters (emission, $510 \mathrm{~nm}$; Chroma Technology, filter set 79001 with a 1.3 neutral density filter). Rhod-2 was imaged using $560 \mathrm{~nm}$ excitation and $630 \mathrm{~nm}$ emission (Chroma Technology, filter set 49008). Calcein Blue was imaged at $350 \mathrm{~nm}$ excitation and $460 \mathrm{~nm}$ emission (Chroma Technology, filter set 31000v2).

To obtain transgenic mice expressing GCaMP3 (Tian et al., 2009) in the cytoplasm of dopaminergic neurons, we crossed the Ai38 floxed GCaMP3 reporter (Zariwala et al., 2012) and DAT ${ }^{\mathrm{IREScre}}$ (Bäckman et al., 2006) mouse lines. DAT ${ }^{\mathrm{IRES}}$ (1) $/ \mathrm{WT}$ heterozygous mice were crossed with heterozygous Ai38 mice and the resulting heterozygous mice for both transgenes were identified by PCR according to protocols provided on the vendor's website and used to produce SN and VTA cultures. Imaging of GCaMP3 was performed with $470 \mathrm{~nm}$ excitation and 525 
$\mathrm{nm}$ emission (Chroma Technology, filter set 49002) at $37^{\circ} \mathrm{C}$.

Comparison of the basal $\mathrm{Ca}^{2+}$ levels in SN and VTA neurons using three different fluorescent reporters yielded conflicting results: Rhod2 fluorescence was significantly higher in untreated SN than VTA neurons (see Results), the difference with GCaMP3 was smaller and did not reach significance, whereas fura-2 showed no difference (Dryanovski et al., 2013). A possible explanation might be the difference in the $\mathrm{Ca}^{2+}$ binding constants between the dyes, which is highest for Rhod2 $(570 \mathrm{nM})$, intermediate for GCaMP3 (405 nM) and lowest for fura-2 (224 nM). Additionally, intracellular compartmentalization of the dyes might be different: GCaMP3 is a cytosolic protein, fura-2 has been shown to localize to other organelles (Takeuchi et al., 1989), while Rhod2 may accumulate into the mitochondria (Hajnóczky et al., 1995). Importantly, however, all three reporters demonstrated the $\mathrm{MPP}^{+}$mediated increase in $\mathrm{Ca}^{2+}$ in SN but not in VTA dopaminergic neurons.

\section{Nitric oxide (NO)}

To determine changes in intracellular NO levels, we used midbrain cultures from TH-mito-roGFP mice and pretreated them with a cell-permeable NO fluorescent indicator, DAR-4M-AM (10 $\mu \mathrm{M}$, Santa Cruz Biotechnology) for $10 \mathrm{~min}$ at $37^{\circ} \mathrm{C}$ before the recordings. Cultures were then rinsed three times with recording saline, mounted in the perfusion chamber $\left(\sim 30^{\circ} \mathrm{C}\right)$, and imaged $30 \mathrm{~min}$ later using $560 \mathrm{~nm}$ excitation and $630 \mathrm{~nm}$ emission filters.

\section{Data analysis}

All electrochemical and optical recordings were performed on sister cultures pretreated with indicated inhibitors and $\mathrm{MPP}^{+}$, except Figure $4 F$, where fluorescent images were taken from the same cells. Statistical analysis was performed in Prism 4 (GraphPad Software; RRID: SCR_002798), using one-way ANOVA followed by a Tukey's post hoc test for comparisons across multiple groups or two-way ANOVA with Bonferroni post hoc test for the paired data. In some cases, data in each experiment performed on sister cultures were normalized to values in control samples and pooled for statistical analysis. Data on all figures are represented as mean \pm SEM. Details of statistical analysis for all datasets are presented in Table 1.

\section{Results}

To address the mechanisms underlying the cell-type selective effects of $\mathrm{MPP}^{+}$exposure, we used cultured primary mouse dopaminergic neurons. We have shown previously that DA neurons in these cultures exhibit intrinsic activity, including tonic and phasic firing, and a voltage sag on brief injection of strong hyperpolarizing currents (Rayport et al., 1992; Dryanovski et al., 2013) similar to those observed in the acute brain slice (Guzman et al., 2010; Tateno and Robinson, 2011; McCutcheon et al., 2012; Roeper, 2013; Avegno et al., 2016; Extended Data Fig. 1-1A,B). Using anatomic criteria, we prepared cultures from either the medial ventral midbrain (VTA) or lateral ventral midbrain (SN). We have previously shown that cultures of SN neurons contain a fraction $(<25 \%)$ of calbindin-positive VTA dopaminergic neurons and vice versa (Mosharov et al., 2009). Using cultures from mice that express green fluorescent protein under the control of the tyrosine hydroxylase promoter (TH-GFP) to identify individual DA neurons, we compared basic electrophysiological properties of cultured SN and VTA neurons. Spontaneous firing frequency measured in cell-attached mode was not different between the two neuronal populations [VTA: $3.8 \pm 0.3 \mathrm{~Hz}(n=8)$; SN: $3.2 \pm 1.0 \mathrm{~Hz}(n=$ 9), $p=0.1388$ by $t$ test]. Whole-cell current-clamp recordings showed slightly higher firing frequency on current injections in SN neurons, but no differences between these two DA neuron populations in rheobase, IV curve, resting membrane potential, input resistance or membrane capacitance (Extended Data Fig. 1-1C-H). Overall, primary DA neurons in culture express biochemical markers and demonstrate morphologic and electrophysiological properties that are comparable to those in acute slice preparations (Branch et al., 2014; Dufour et al., 2014). Thus, this system, which excludes extraneuronal contributors to MPTP toxicity, is sufficiently robust to study intraneuronal factors that lead to $\mathrm{MPP}^{+}$-mediated cell death. To reduce variability and minimize the potential effect of neuronal dedifferentiation, experiments were performed on sister cultures of SN and VTA neurons with the expression of dopaminergic markers (TH or DAT) confirmed in live or postfixed cells.

Exposure of cultured ventral midbrain neurons to a range of $\mathrm{MPP}^{+}$concentrations confirmed that, as in vivo, SN neurons were far more sensitive to the toxin than VTA neurons (Fig. 1A; Extended Data Fig. 1-2), similar to other reports (Pacelli et al., 2015). Significant differences were also observed in the time course of toxicity, with most cell death occurring on the first day of exposure in VTA neurons and over $3 \mathrm{~d}$ in the SN cultures (Fig. 1B).

\section{DAT activity in SN and VTA neurons}

Why are SN neurons more susceptible to $\mathrm{MPP}^{+}$? To investigate whether increased intracellular accumulation of the toxin is responsible, we compared DAT activity between individual SN and VTA neurons using optical and electrochemical approaches. First, we used a recently characterized fluorescent structural analog of the toxin, $\mathrm{APP}^{+}$, that selectively accumulates in dopaminergic cells via DAT (Fig. 1C), where it co-localizes with mitochondrial markers (Karpowicz et al., 2013). Analysis of APP ${ }^{+}$uptake (total cell body fluorescence intensity) revealed that $\mathrm{SN}$ neurons indeed possessed $\sim 40 \%$ higher DAT activity than VTA neurons $(396.6 \pm 24.4$ vs $237.6 \pm 8.4$ A.U.; $p<$ 0.001 by $t$ test), but a similar $\mathrm{K}_{0.5}$ of the uptake $(16.9 \pm 5.5$ vs $15.9 \pm 5 \mu \mathrm{M}$; n.s.; Fig. $1 D$; Extended Data Fig. 1-3).

As an independent approach to compare DAT function, we employed IPE. In this technique, a CFE is positioned inside a glass patch pipette (Extended Data Fig. 1-4). After a high resistance seal is achieved, the cellular membrane is ruptured and diffusing cytosolic metabolites produce a wave of oxidation at the electrode (Mosharov et al., 2003). To measure $\mathrm{DA}_{\text {cyt }}$, we used IPE in cyclic voltammetric mode, which provides a means to distinguish oxidizable 
Table 1 Details of statistical analyses between all experimental groups presented in the paper.

\begin{tabular}{|c|c|c|c|c|c|}
\hline Figure & Test used & $n$ & Defined & $p$ value & $F / t$ value \\
\hline $1 A$ & Two-way ANOVA & VTA: $23,13,15,14 ; \mathrm{SN}-16,9,12,10$ & Dishes from 12 independent experiments & $p<0.0001$ & $F_{(1,104)}=412.4$ \\
\hline $1 B$ & Two-way ANOVA & VTA: $3,5,5,3,3 ;$ SN- $5,4,2,6,3$ & Cultures from 2 independent experiments & $p<0.0001$ & $F_{(1,29)}=109.5$ \\
\hline $1 E$ & Unpaired $t$ test & 4,4 & Cells in each group & $p=0.0294$ & $t_{(6)}=2.84$ \\
\hline $2 B$, VTA & One-way ANOVA & $16,8,6,7,6,6$ & VTA dishes from 8 independent experiments & $p<0.0001$ & $F_{(5,41)}=15.5$ \\
\hline $2 B, S N$ & One-way ANOVA & $17,16,7,8,10,9$ & SN dishes from 9 independent experiments & $p<0.0001$ & $F_{(5,61)}=93.56$ \\
\hline $2 C$ & Two-way ANOVA & VTA: $16,8,15,6,13 ; \mathrm{SN}-11,6,10,5$ & Dishes from 6 independent experiments & $p<0.001$ & $F_{(1,69)}=12.0$ \\
\hline $2 E$ & One-way ANOVA & $14,17,26,23$ & Cells from 2 independent experiments & $p<0.0001$ & $F_{(3,76)}=14.47$ \\
\hline $2 G$ & One-way ANOVA & $40,29,106,75$ & Cells from 14 independent experiments & $p<0.0001$ & $F_{(3,246)}=78.69$ \\
\hline $2 H$ & Two-way ANOVA & VTA: $40,27,25,30 ;$ SN: 70, 54, 22, 23 & Cells from 11 independent experiments & $p<0.0001$ & $F_{(1,283)}=206.7$ \\
\hline $3 A$ & Two-way ANOVA & $\begin{array}{l}\text { VTA: } 33,6,29,16,11,19,33,7,10,19,11 \\
15 ; \text { SN: } 34,16,18,17,11,16,34,8,19,24,18,12\end{array}$ & Cells from 8 independent experiments & $p<0.0001$ & $F_{(3,412)}=43.15$ \\
\hline $3 B$ & Unpaired $t$ test & 6,8 & Cells from 2 independent experiments & $p<0.05$ & $t_{(12)}=3.52$ \\
\hline $3 D$ & Two-way ANOVA & VTA: $71,27,38,11 ;$ SN: $57,24,35,23$ & Cells from 7 independent experiments & $p<0.0001$ & $F_{(1,278)}=73.09$ \\
\hline $4 B$ & Two-way ANOVA & VTA: $23,14,24,24 ;$ SN: $51,36,22,9$ & Cells from 4 independent experiments & $p<0.0001$ & $F_{(1,195)}=101.1$ \\
\hline $4 C$ & One-way ANOVA & VTA: $46,23,51,35 ;$ SN: $68,11,100,59,92,48,29,41,43$ & Cells from 14 independent experiments & $p<0.0001$ & $F_{(12,633)}=60.75$ \\
\hline $4 D$ & One-way ANOVA & VTA: 67,$37 ;$ SN: $68,48,37$ & Cells from 3 independent experiments & $p<0.0001$ & $F_{(4,192)}=9.16$ \\
\hline $5 C$ & One-way ANOVA & VTA: 36,$57 ;$ SN: 75, 46, 54, 20, 42, 28, 28 & Cells from 8 independent experiments & $p<0.0001$ & $F_{(8,377)}=52.62$ \\
\hline $5 E$ & One-way ANOVA & VTA: 24,$28 ;$ SN: 18, 26, 29 & Cells from 3 independent experiments & $p<0.0001$ & $F_{(4,120)}=9.32$ \\
\hline $6 A$ & One-way ANOVA & VTA: $9,10,10,9 ; \mathrm{SN}: 25,28,14,9,10,10$ & Cells from 4 independent experiments & $p<0.0001$ & $F_{(9,124)}=40.1$ \\
\hline $6 B$ & One-way ANOVA & VTA: $64,42,25 ;$ SN: $54,38,20$ & Cells from 7 independent experiments & $p<0.0001$ & $F_{(5,127)}=31.04$ \\
\hline $6 C$ & One-way ANOVA & $80,26,15,21,78,33,29,43,22,21$ & Cells from 14 independent experiments & $p<0.0001$ & $F_{(9,358)}=20.75$ \\
\hline $6 D$ & Two-way ANOVA & $16,20,18,16$ & Cells from 2 independent experiments & $p=0.4593$ & $F_{(1,66)}=0.55$ \\
\hline $7 A$ & One-way ANOVA & $24,15,22,12$ & Cells from 5 independent experiments & $p<0.0001$ & $F_{(3,246)}=78.69$ \\
\hline $7 B$ & One-way ANOVA & $24,44,25,17,38,27,33,9,19$ & Cells from 15 independent experiments & $p<0.0001$ & $F_{(8,227)}=13.69$ \\
\hline $7 C$ & One-way ANOVA & $14,17,23$ & Cells from 3 independent experiments & $p<0.0001$ & $F_{(2,51)}=19.0$ \\
\hline $7 D$, VTA & One-way ANOVA & $16,10,5,3$ & Dishes from 5 independent experiments & $p<0.0001$ & $F_{(3,30)}=12.28$ \\
\hline $7 D, \mathrm{SN}$ & One-way ANOVA & $17,23,8,8,6$ & Dishes from 7 independent experiments & $p<0.0001$ & $F_{(4,57)}=139.2$ \\
\hline $7 F$ & One-way ANOVA & VTA: $26,23,22 ;$ SN: $16,23,22$ & Cells from 2 independent experiments & $p<0.05$ & $F_{(5,126)}=13.89$ \\
\hline $7 G$ & One-way ANOVA & $22,28,25,10,6,6,10$ & Dishes from 13 independent experiments & $p<0.0001$ & $F_{(6,99)}=157.6$ \\
\hline $7 H$ & One-way ANOVA & VTA: $12,12,13 ; \mathrm{SN}: 7,7,8$ & Dishes from 4 independent experiments & $p<0.0001$ & $F_{(5,53)}=95.53$ \\
\hline $8 A$ & One-way ANOVA & WT: $16,12,8 ; \mathrm{KO}: 14,11,6$ & Dishes from 3 independent experiments & $p<0.0001$ & $F_{(5,58)}=80.15$ \\
\hline $8 B$ & One-way ANOVA & $23,15,6,6$ & Dishes from 2 independent experiments & $p<0.01$ & $F_{(3,46)}=14.12$ \\
\hline $8 C$ & Two-way ANOVA & WT: 18, 20, 18; KO: 20, 16, 24 & Cells from 2 independent experiments & $p=0.4988$ & $F_{(1,110)}=0.46$ \\
\hline $8 D$ & One-way ANOVA & $104,124,41,83$ & Cells from 5 independent experiments & $p<0.0001$ & $F_{(3,348)}=59.46$ \\
\hline $8 E$ & One-way ANOVA & $18,26,18,19$ & Cells from 3 independent experiments & $p<0.0001$ & $F_{(3,77)}=8.15$ \\
\hline $8 F$ & Two-way ANOVA & WT: $7,10,15 ; \mathrm{KO}: 7,10,10$ & Cells from 3 independent experiments & $p<0.0001$ & $F_{(1,53)}=20.67$ \\
\hline $9 B$ & One-way ANOVA & $97,104,127,83$ & Cells from 2 independent experiments & $p<0.0001$ & $F_{(3,407)}=224.8$ \\
\hline $9 C$ & One-way ANOVA & $97,104,38,41$ & Cells from 3 independent experiments & $p<0.0001$ & $F_{(3,276)}=32.04$ \\
\hline $9 D$ & One-way ANOVA & Ctrl: 75, 54, 20; mKate: 40, 42; hWT: 50, 52, 54 & Cells from 4 independent experiments & $p<0.0001$ & $F_{(7,379)}=63.87$ \\
\hline $9 E$ & One-way ANOVA & Ctrl: 36, 57, 61; mKate: 21, 21; hWT: 64, 64, 33 & Cells from 4 independent experiments & $p=0.7016$ & $F_{(7,349)}=0.67$ \\
\hline \multicolumn{6}{|c|}{ Extended Data figures } \\
\hline $1-1 C$ & Two-way ANOVA & VTA:13; SN: 11 & Cells in 2 independent experiments & $p<0.01$ & $F_{(1,392)}=9.85$ \\
\hline $1-1 D$ & Mann-Whitney & 13,11 & Cells in 2 independent experiments & $p=0.506$ & $U=60.5$ \\
\hline $1-1 E$ & Two-way ANOVA & VTA: 13; SN: 11 & Cells in 2 independent experiments & $p=0.053$ & $F_{(1,175)}=3.79$ \\
\hline $1-1 F$ & Mann-Whitney & 15,11 & Cells in 2 independent experiments & $p=0.643$ & $U=80.0$ \\
\hline $1-1 G$ & Mann-Whitney & 14,12 & Cells in 2 independent experiments & $p=0.699$ & $U=76.0$ \\
\hline $1-1 H$ & Mann-Whitney & 14,12 & Cells in 2 independent experiments & $p=0.625$ & $U=74.0$ \\
\hline $1-2 A$ & Two-way ANOVA & $\begin{array}{l}\text { WT: } 16,12,10 \text {; THGFP: } 6,5,5,5 \text {; THmito: } \\
6,5,5,5 \text {; DATGCaMP: } 6,5,5,5\end{array}$ & Cells from 6 independent experiments & $p=0.4232$ & $F_{(3,74)}=0.95$ \\
\hline $1-2 B$ & Two-way ANOVA & $\begin{array}{l}\text { WT: } 23,15,14 \text {; THGFP: } 6,5,5,5 \text {; THmito: } \\
6,5,6,5 \text {; DATGCaMP: } 6,5,5,5\end{array}$ & Cells from 6 independent experiments & $p=0.9491$ & $F_{(3,89)}=0.12$ \\
\hline $4-1$ & Unpaired $t$ test & 33,32 & Cells from 2 independent experiments & $p=0.8678$ & $t_{(63)}=0.1675$ \\
\hline $5-1 B$ & Two-way ANOVA & VTA: $18,8,26 ;$ SN: $34,7,37 ;$ effect of the drug & Cells from 4 independent experiments & $p<0.002$ & $F_{(2,131)}=6.61$ \\
\hline $5-1 B$ & Two-way ANOVA & VTA: $18,8,26 ;$ SN: $34,7,37$; effect between the cell types & Cells from 4 independent experiments & $p=0.1429$ & $F_{(1,131)}=2.17$ \\
\hline $5-1 C$ & One-way ANOVA & $36,24,57,61$ & Cells from 7 independent experiments & $p=0.1601$ & $F_{(3,174)}=1.74$ \\
\hline $5-2$ & One-way ANOVA & $68,100,59,28,29,14$ & Cells from 7 independent experiments & $p<0.0001$ & $F_{(5,292)}=37.02$ \\
\hline $6-1$ & One-way ANOVA & $33,25,9,27,30$ & Cells from 6 independent experiments & $p<0.0001$ & $F_{(4,119)}=9.47$ \\
\hline $6-2$ & One-way ANOVA & $74,27,75,33,24,40$ & Cells from 8 independent experiments & $p<0.0001$ & $F_{(5,267)}=26.46$ \\
\hline
\end{tabular}

compounds based on their redox profile. We preincubated cells for $1 \mathrm{~h}$ with $10 \mu \mathrm{M}$ DA in the presence of the monoamine oxidase (MAO) and vesicular monoamine transporter 2 (VMAT) blockers pargyline and reserpine to prevent intracellular DA breakdown and vesicular uptake, respectively. We then measured the concentration of neuronal $\mathrm{DA}_{\mathrm{cyt}}$ in the presence or absence of the competitive DAT inhibitor, nomifensine. Comparison of the nomifensine-sensitive portion of intracellular DA accumulation confirmed that SN neurons exhibit $\sim 40 \%$ higher DAT activity (Fig. 1E).

To further investigate the relationship between DAT activity and $\mathrm{MPP}^{+}$-mediated toxicity, we compared $\mathrm{APP}^{+}$ uptake and neuroprotection in SN neurons pretreated with a range of nomifensine concentrations to partially block DAT. A far lower concentration of nomifensine was required to block $\mathrm{APP}^{+}$uptake $\left(\mathrm{IC}_{50}\right.$ of $\left.\sim 250 \mathrm{nM}\right)$ than to achieve a half-maximal effect on cell survival $(\sim 2 \mu \mathrm{M}$; 
A

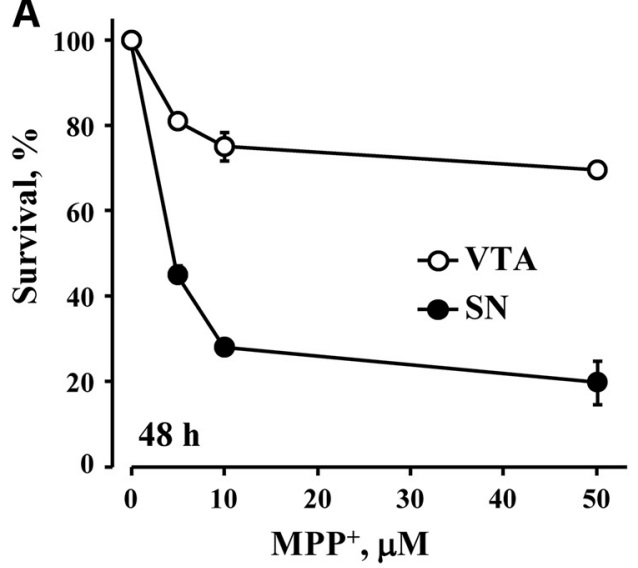

C

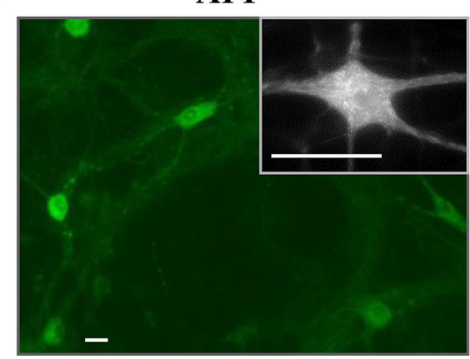

D

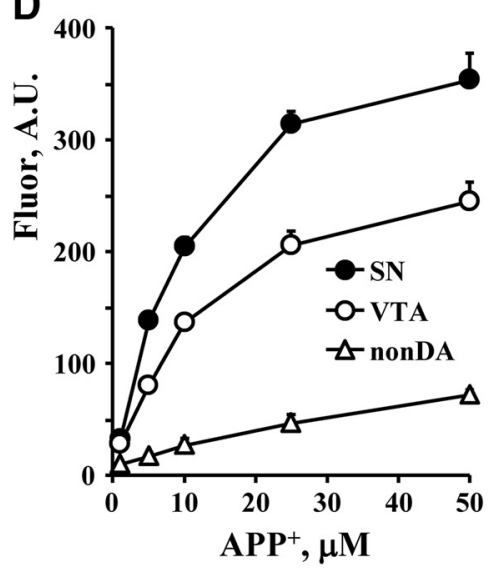

E
B

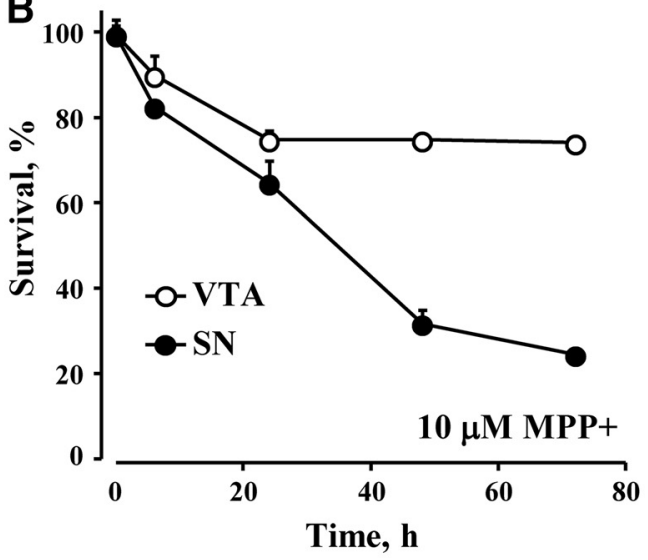

TH

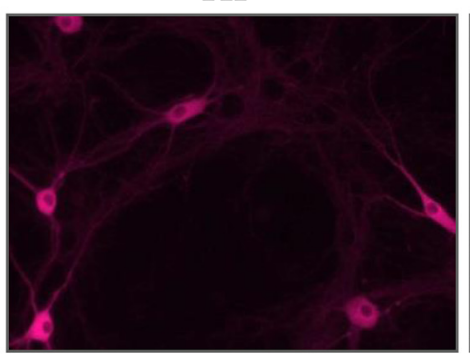

Brightfield

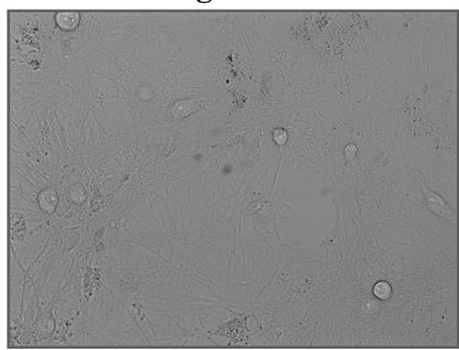

F

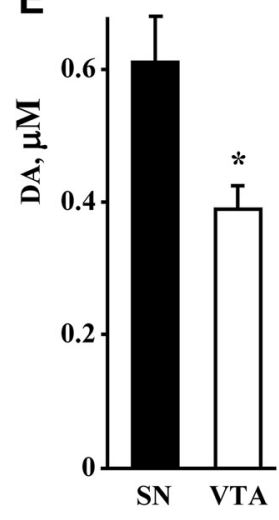

Figure 1. $\mathrm{MPP}^{+}$-induced toxicity in cultured SN and VTA DA neurons. $\boldsymbol{A}$, Neurotoxicity following a 2-d exposure of primary cultures of mouse WT SN and VTA neurons to different concentrations of $\mathrm{MPP}^{+}$. DA neurons were tallied following fixation and immunostaining for $\mathrm{TH} ; p<0.001$ by two-way ANOVA ( $n=9-23$ dishes in each group from 12 independent experiments). Basal electrophysiological characteristics of cultured mouse midbrain neurons are shown in Extended Data Figure 1-1. MPP ${ }^{+}$-mediated toxicity in neuronal cultures from different mouse strains is shown in Extended Data Figure 1-2. B. Time course of toxicity in cultures treated with $10 \mu \mathrm{M}$ MPP $; p<$ 0.001 by two-way ANOVA ( $n=3-6$ dishes from two independent experiments). $\boldsymbol{C}$, Representative images of midbrain cultures treated with $5 \mu \mathrm{M} \mathrm{APP}^{+}$for $10 \mathrm{~min}$ and then fixed and stained for TH. All APP ${ }^{+}$-positive cells were $\mathrm{TH}$-positive, whereas $95 \%$ of TH-positive neurons were $\mathrm{APP}^{+}$-positive $(n=17)$. Inset demonstrates punctate $\mathrm{APP}^{+}$staining in neuronal somas and processes. Scale bar: $10 \mu \mathrm{m}$. $\boldsymbol{D}$, Concentration dependence of $\mathrm{APP}^{+}$uptake into SN and VTA neurons, as well as non-DA cell in the same cultures. Lineweaver-Burk plot of the data are shown in Extended Data Figure 1-3. E. Average nomifensine-sensitive (10 $\mu \mathrm{M} ; 30 \mathrm{~min})$ part of DA uptake into SN and VTA neurons pretreated for 30 min with MAO and VMAT inhibitors pargyline (10 $\mu \mathrm{M})$ and reserpine $(2 \mu \mathrm{M})$, correspondingly, and then treated with $10 \mu \mathrm{M}$ DA for $1 \mathrm{~h}\left(p<0.05\right.$ by $t$ test). $\mathrm{DA}_{\text {cyt }}$ concentrations were determined by IPE in the cyclic voltammetric mode of detection (Extended Data Fig. 1-4). F, Dependence of $\mathrm{APP}^{+}$uptake (left axis) and survival of MPP ${ }^{+}$-treated SN neurons (right axis) on nomifensine concentration. For DAT activity assay, cells were preincubated with nomifensine for $30 \mathrm{~min}$, and then exposed to $10 \mu \mathrm{M}$ APP ${ }^{+}$for another $10 \mathrm{~min}$. Fluorescence intensity of the cell bodies was quantified, background subtracted and normalized to that in nomifensine-untreated $\mathrm{SN}$ neurons. The $\mathrm{IC}_{50}$ of the DAT inhibition is $\sim 250 \mathrm{nM}$ nomifensine. Toxicity was measured following cell incubation with indicated concentrations of nomifensine and $10 \mu \mathrm{M} \mathrm{MPP}^{+}$. Zero toxicity rescue corresponds to the levels of $\mathrm{MPP}^{+}$toxicity in the absence of nomifensine, and $100 \%$ to that in untreated $\mathrm{SN}$ neuronal cultures. The $\mathrm{IC}_{50}$ of the nomifensine-mediated rescue of SN neurons is $\sim 2 \mu \mathrm{M}$. Left and right diamonds represent DAT activity and toxicity in VTA neurons, respectively. 
Fig. $1 F$ ). In fact, the nomifensine concentration that decreased DAT activity in SN neurons to the level of VTA neurons decreased toxicity by only $\sim 10 \%$. Conversely, to achieve the same level of toxicity as in VTA neurons, DAT uptake needed to be blocked by $\sim 90 \%$ in $\mathrm{SN}$ neurons (Fig. $1 F$, diamonds), suggesting that while DAT is essential for $\mathrm{MPP}^{+}$toxicity, additional intrinsic factors play a major role in differential sensitivity of SN and VTA DA neurons to $\mathrm{MPP}^{+}$.

\section{Different mechanisms of MPP ${ }^{+}$toxicity in $\mathrm{SN}$ and VTA neurons}

$\mathrm{MPP}^{+}$has been reported to target multiple intracellular systems, particularly Complex I of the mitochondrial electron transport chain (ETC), NO synthesis and DA homeostasis (Fig. 2A), although the role of these pathways is debated (Hasbani et al., 2005; Kim et al., 2015). Interestingly, we found that the contribution from each of the pathways to toxicity was remarkably different between $\mathrm{SN}$ and VTA DA neurons (Fig. 2B). Whereas depletion of intracellular DA with the aromatic L-amino acid decarboxylase (AADC) inhibitor, benserazide (Bsrz; $10 \mu \mathrm{M}$; 48-h preincubation), provided partial protection of $\mathrm{SN}$ neurons, it had no effect on the survival of VTA neurons treated with $\mathrm{MPP}^{+}$. In contrast, succinate $(1 \mathrm{mM} ; 30$-min preincubation), a Complex II substrate that bypasses $\mathrm{MPP}^{+}$mediated inhibition of Complex I (Lotharius and O'Malley, 2000), was ineffective at rescuing SN neurons, but prevented the death of VTA neurons. The NO synthase (NOS) blocker, L-NAME (100 $\mu \mathrm{M}$; 1-h preincubation), protected both SN and VTA neurons, albeit with different efficiency. This demonstrates that the different levels of $\mathrm{MPP}^{+}$induced toxicity between SN and VTA neurons arise from different toxicity mechanisms engaged by $\mathrm{MPP}^{+}$. To determine if sensitivity to Complex I inhibition might contribute to the differential toxicity observed between $\mathrm{SN}$ and VTA cultures, we examined the effect of a highly selective and potent Complex I inhibitor, piericidin A (Choi et al., 2011). We found that toxicity was indeed higher in SN than VTA neurons, although the difference was much smaller than for MPP ${ }^{+}$(Fig. 2C). Thus, at least a portion of the different responses of the two cell types to stress can be attributed to elevated sensitivity of $\mathrm{SN}$ neurons to mitochondrial ETC blockade.

Consistent with previously reported $\mathrm{MPP}^{+}$-induced cellular oxidative stress (Lotharius and O'Malley, 2000), we found that the glutathione precursor $\mathrm{N}$-acetyl cysteine (200 $\mu$ M; 2-h preincubation) rescued both SN and VTA neurons from $\mathrm{MPP}^{+}$(Fig. 2B). To further determine the effects of the toxin on mitochondrial oxidation, we used neuronal cultures from mice that express a mitochondriatargeted redox sensitive GFP under the control of the tyrosine hydroxylase promoter (TH-mito-roGFP; Guzman et al., 2010). While untreated cells displayed a mesh-like mitochondrial network in cell bodies and elongated mitochondria in processes, $\mathrm{MPP}^{+}$exposure for $2 \mathrm{~h}$ induced the formation of rounded mitochondria in the soma and axons, indicative of mitochondrial stress (Fig. 2D,E). MitoroGFP provides ratiometric measurements of mitochondrial oxidation that are independent of the protein's expression levels. As expected, 410/470 nm fluorescence ratios of completely reduced or oxidized roGFP were the same in SN and VTA neurons, however, the signal differed significantly in living cells (Fig. 2F). Furthermore, after $\mathrm{MPP}^{+}$treatment, roGFP oxidation was higher (Fig. 2G) and lasted longer (Fig. $2 \mathrm{H}$ ) in $\mathrm{SN}$ neurons, revealing the presence of cell type-specific mitochondrial oxidative stress.

As inhibition of DA synthesis was more effective at rescuing $\mathrm{SN}$ neurons, we investigated if $\mathrm{MPP}^{+}$-induced changes in DA homeostasis may underlie higher sensitivity of these cells to the toxin. Using cultures from TH-GFP mice, we measured DA $\mathrm{cyt}_{\text {cy }}$ using IPE in CV mode (Mosharov et al., 2003). Cultures were pretreated with the DA precursor, L-DOPA (100 $\mu \mathrm{M}, 30 \mathrm{~min})$, to increase $\mathrm{DA}_{\text {cyt }}$ to levels detectable by IPE, and the time course of changes in $\mathrm{DA}_{\mathrm{cyt}}$ was determined in cells exposed to 10 or $50 \mu \mathrm{M}$ $\mathrm{MPP}^{+}$. We found significantly higher $\mathrm{DA}_{\mathrm{cyt}}$ in $\mathrm{SN}$ neurons at both neurotoxin concentrations (Fig. $3 A$ ). To confirm that differences in $\mathrm{DA}_{\mathrm{cyt}}$ did not require L-DOPA, we also measured $\mathrm{DA}_{\mathrm{cyt}}$ in L-DOPA-untreated neurons. Although the levels of $\mathrm{DA}_{\text {cyt }}$ were much lower, $\mathrm{MPP}^{+}$still induced a far greater increase in $\mathrm{DA}_{\text {cyt }}$ in SN compared to VTA neurons (Fig. 3B)

Activation of NOS and generation of peroxynitrite have been implicated in mediating MPP ${ }^{+}$toxicity (Schulz et al., 1995; Przedborski et al., 1996). We, therefore, determined the levels of neuronal NO using the fluorescent reporter DAR-4M-AM, which revealed significantly higher NO levels in SN than VTA DA neurons both before and after toxin exposure (Fig. 3C,D).

\section{Upregulation of $\mathrm{Ca}^{2+}$ in $\mathrm{SN}$ neurons exposed to MPP $^{+}$}

Higher levels of $\mathrm{DA}_{\text {cyt }}$ in $\mathrm{SN}$ neurons may result from $\mathrm{Ca}^{2+}$-mediated upregulation of DA synthesis via AADC (Mosharov et al., 2009). Similarly, neuronal NOS (nNOS) is regulated by $\mathrm{Ca}^{2+}$ via calmodulin-mediated phosphorylation (Förstermann et al., 1991; Sanchez-Padilla et al., 2014). To examine whether changes in $D A_{c y t}$ and $N O$ in $\mathrm{MPP}^{+}$-treated neurons were driven by increased $\mathrm{Ca}^{2+}$ levels, we employed several fluorescent $\mathrm{Ca}^{2+}$ reporters.

Comparison of the accumulation of Calcein Blueacetoxymethyl (AM), a dye sensitive to $\mathrm{Ca}^{2+}$ only at highly alkaline $\mathrm{pH}$ (Huitink et al., 1974), confirmed that AM modified dye uptake and esterase activity were similar in SN and VTA neurons (Extended Data Fig. 4-1). In contrast, fluorescence intensity of the $\mathrm{Ca}^{2+}$-sensitive probe Rhod-2 increased sharply in SN neurons treated with $\mathrm{MPP}^{+}$for 2 $\mathrm{h}$, returning to pretreatment levels after $6 \mathrm{~h}$ of exposure (Fig. $4 A, B$ ). Importantly, both basal and maximal $\mathrm{Ca}^{2+}$ concentrations were higher in SN than VTA neurons and were sensitive to dihydropyridine treatment (Fig. 4C), suggesting that LTCC are critical mediators of these differences. A similar increase in free $\mathrm{Ca}^{2+}$ in $\mathrm{SN}$ neurons exposed to MPP ${ }^{+}$and its blockade by an LTCC inhibitor, nimodipine, were observed with the ratiometric probe fura-2 (Fig. 4D), although this dye showed no difference in the basal $\mathrm{Ca}^{2+}$ levels in SN and VTA neurons (see Methods). In contrast, restoring ETC function with succinate or 

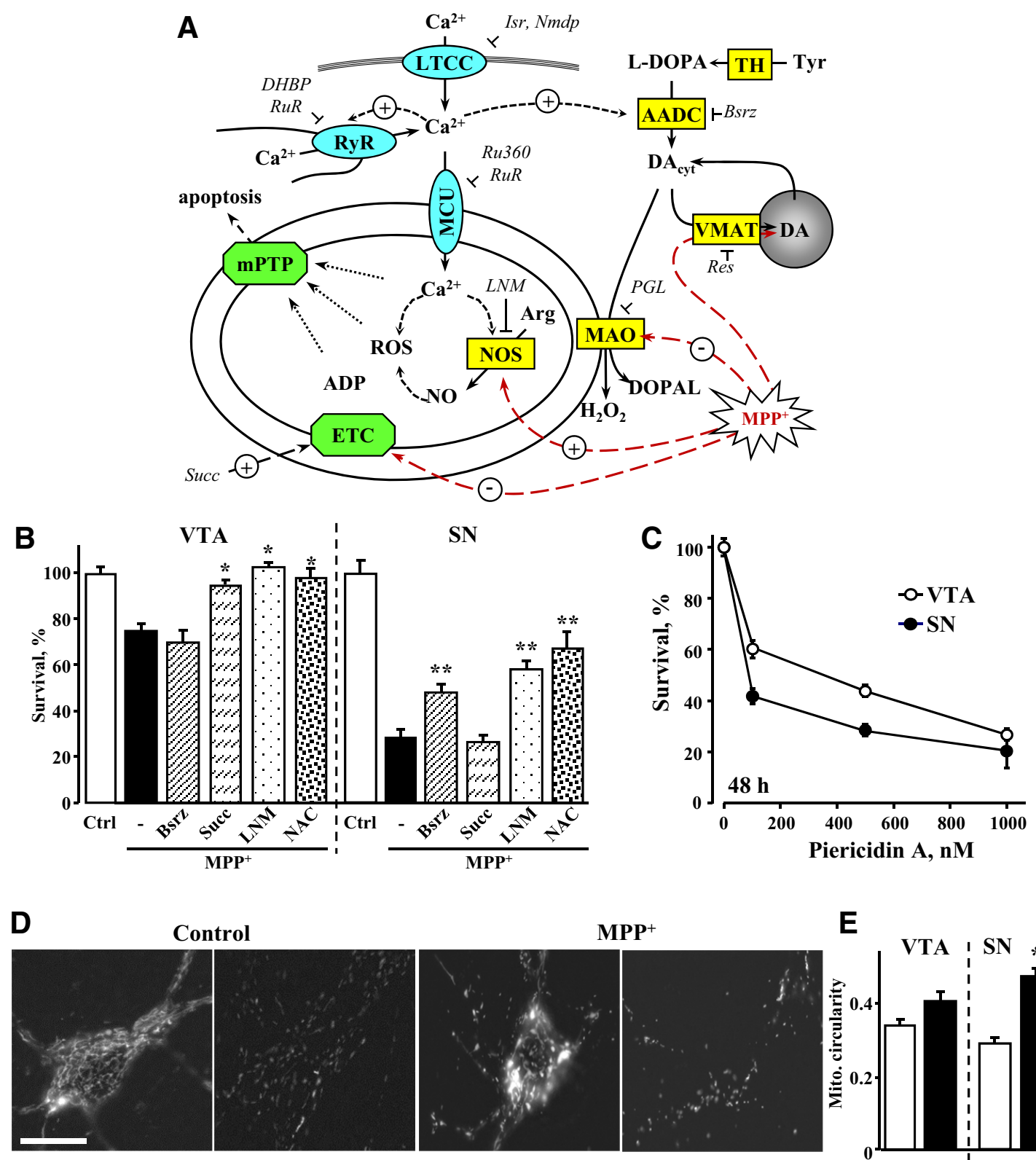

$\mathbf{M P P}^{+}$

\section{$\mathbf{E}$}
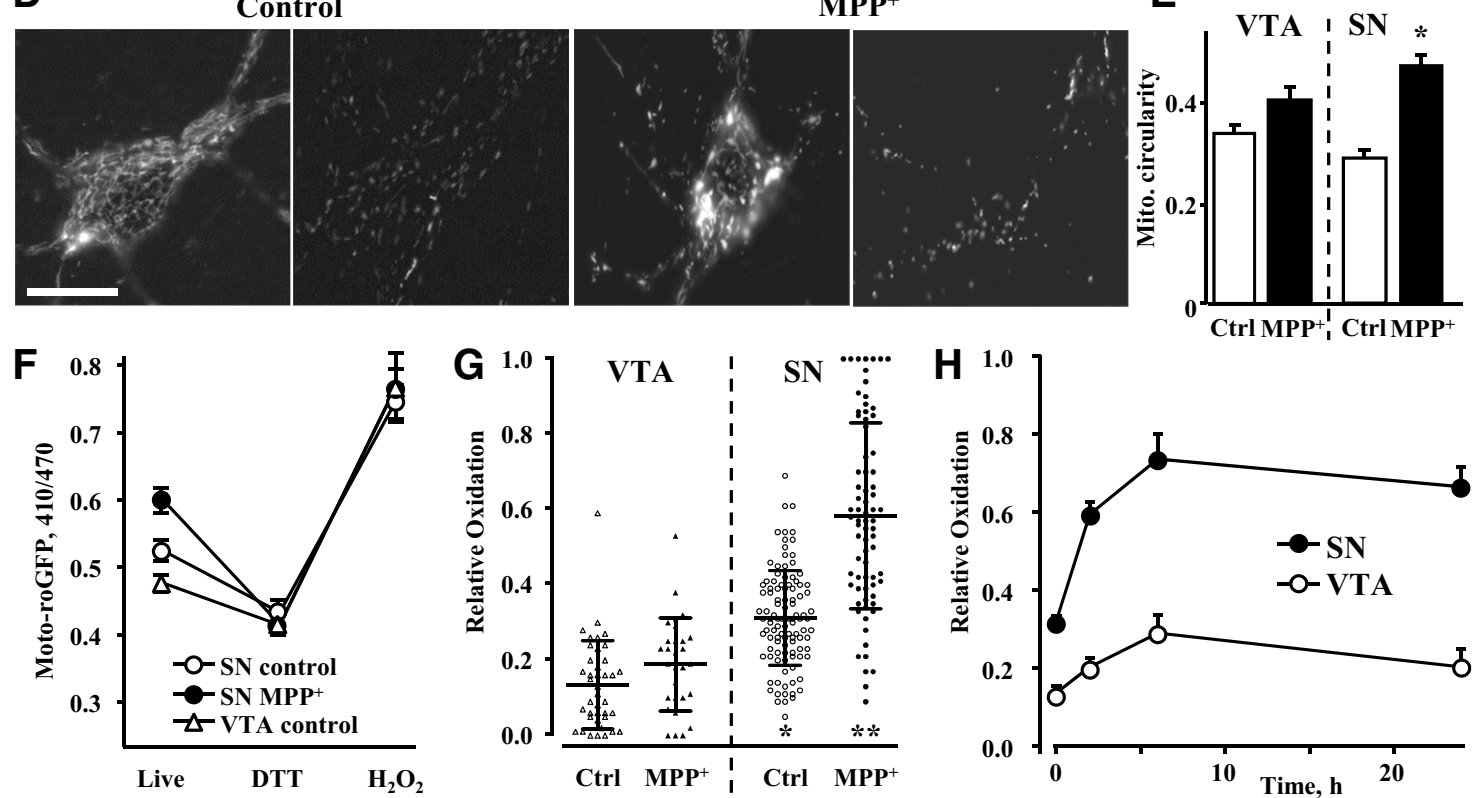

Figure 2. Difference in mechanisms of $\mathrm{MPP}^{+}$-induced toxicity in SN and VTA neurons. $\boldsymbol{A}$, Schematics of possible MPP ${ }^{+}$toxicity pathways. Abbreviations, concentrations of drugs, and preincubation times used for pharmacological analysis: AADC, aromatic L-amino acid decarboxylase; Arg, arginine; ADP, adenosine diphosphate; Bsrz, benserazide (10 $\mu \mathrm{M}, 48 \mathrm{~h}) ; \mathrm{Ca}$ 1.3, voltage-gated L-type calcium channel; DHBP, 1,1'-diheptyl-4,4'-bipyridinium dibromide (100 $\mu \mathrm{M}, 30$ min); DOPAL, 3,4-dihydroxyphenylacetaldehyde; Isr, isradipine (5 $\mu \mathrm{M}, 30 \mathrm{~min})$; L-DOPA, L-3,4-dihydroxyphenylalanine (100 $\mu \mathrm{M}, 30 \mathrm{~min})$; LNM, NG-nitro-L-arginine methyl ester (L-NAME; $100 \mu \mathrm{M}, 1 \mathrm{~h}$ ); mPTP, mitochondrial permeability transition pore; Nmdp, nimodipine (5 $\mu \mathrm{M}, 30 \mathrm{~min})$; Res, reserpine (10 $\mu \mathrm{M}$, 
continued

24 h); ROS, reactive oxygen species; Ru360 (10 $\mu$ M, 30 min); RuR, ruthenium red (20 $\mu$ M, 24 h); Succ, succinate (Complex II substrate; $1 \mathrm{mM}, 1 \mathrm{~h}) ; \mathrm{TH}$, tyrosine hydroxylase. Channels are shown in turquoise, enzymes and transporters in yellow and protein complexes in green. $\boldsymbol{B}$, Pharmacological analysis of known mechanisms of MPP ${ }^{+}$toxicity in VTA and SN DA neurons. Cultures were treated with various pharmacological agents as described above followed by $10 \mu \mathrm{M} \mathrm{MPP}^{+}$; surviving TH-positive neurons were tallied $48 \mathrm{~h}$ later. None of the compounds were neurotoxic when applied without MPP ${ }^{+} ; p<0.05$ from $\mathrm{MPP}^{+}(*)$ or both MPP $\mathrm{MP}^{+}$and control (**) by one-way ANOVA with Tukey's post hoc test ( $n=6-16$ for VTA and 7-17 for SN dishes from 12 independent experiments). $\boldsymbol{C}$, Dependence of survival of SN and VTA DA neurons on the concentration of mitochondrial Complex I inhibitor pierecidin A. Following $2 \mathrm{~d}$ of exposure, neurons were fixed with paraformaldehyde, immunostained for TH and tallied; $p<0.001$ by two-way ANOVA ( $n=$ 5-16 dishes in each group from six independent experiments). $\boldsymbol{D}$, Representative images of TH-mito-roGFP SN neuronal cell bodies (left) and axons (right) before and after 2 h of treatment with $50 \mu \mathrm{M} \mathrm{MPP}{ }^{+}$. Scale bar: $5 \mu \mathrm{m}$. $\boldsymbol{E}$, Changes in mitochondria circularity in SN and VTA neurons treated with $50 \mu \mathrm{M} \mathrm{MPP}^{+}$for $2 \mathrm{~h} ; * p<0.05$ from untreated cells by one-way ANOVA with Tukey's post hoc test ( $n=14-22$ cells from two independent experiments). $\boldsymbol{F}$, Average roGFP $410 / 470$ fluorescence ratios in the somas of neurons either before (live) or after treatment with $1 \mathrm{mM}$ DTT (middle) followed by $2 \mathrm{mM} \mathrm{H}_{2} \mathrm{O}_{2}$ (right; $n=18-21$ cells from three independent experiments). G, Relative oxidation of VTA and SN neurons before and after treatment with $50 \mu \mathrm{M}$ MPP for 2 h; $p<0.05$ from control VTA (*) or control SN (**) by one-way ANOVA with Tukey's post hoc test $(n=29-106$ cells from 14 independent experiments). Horizontal bars represent means and SDs. $\boldsymbol{H}$, Time-dependent changes in mitochondrial oxidation in SN and VTA neurons treated with $50 \mu \mathrm{M} \mathrm{MPP}^{+} ; p<0.001$ by two-way ANOVA ( $n=22-70$ cells from 11 independent experiments). Neurotoxin was added at time 0 .

alleviating cellular oxidative stress with NAC did not counter the toxin-induced elevation of $\mathrm{Ca}^{2+}$ (Fig. 4C). For further analysis, we used $10 \mu \mathrm{M} \mathrm{MPP}{ }^{+}$for neurotoxicity assays ( $2 \mathrm{~d}$ of exposure) and $50 \mu \mathrm{M} \mathrm{MPP}{ }^{+}$for acute metabolic assays $(2 \mathrm{~h})$, as the higher $\mathrm{MPP}^{+}$concentration induced a slightly more robust response in $\mathrm{DA}_{\text {cyt }}$ (Fig. $3 A$ ) and $\mathrm{Ca}^{2+}\left(201 \pm 15 \%(n=47)\right.$ increase in $\mathrm{Ca}^{2+}$ for $10 \mu \mathrm{M}$ versus $246 \pm 13 \%(n=100)$ for $50 \mu \mathrm{M}$ relative to untreated SN neurons).

To monitor cytosolic $\mathrm{Ca}^{2+}$ alterations in the same neurons before and after toxin exposure, we employed midbrain cultures from DAT-GCaMP3 mice (Fig. 5A). Cultured DA neurons often show $\mathrm{Ca}^{2+}$ transients that can be observed for several hours under our imaging conditions (Extended Data Fig. 5-1A). After 30 min of $\mathrm{MPP}^{+}$exposure, the frequency of transients and basal $\mathrm{Ca}^{2+}$ levels decreased in both SN and VTA neurons (Fig. 5B; Extended Data Fig. 5-1B). In contrast to VTA neurons where GCaMP3 fluorescence did not change after the initial decrease, $\mathrm{Ca}^{2+}$ levels increased markedly in $\mathrm{SN}$ neurons treated with $\mathrm{MPP}^{+}$for $2 \mathrm{~h}$, although the response varied between cells. Consistent with the Rhod2 data, pretreatment with isradipine prevented $\mathrm{MPP}^{+}$-induced $\mathrm{Ca}^{2+}$ elevation in SN (Fig. 5C), but not VTA (Extended Data Fig. 5-1C) DA neurons.

Because of a reported interaction between LTCC and RyR in the brain (Chavis et al., 1996; Sanchez-Padilla et al., 2014), we investigated whether the latter were involved in mediating the increase in $\mathrm{Ca}^{2+}$ following $\mathrm{MPP}^{+}$exposure. We inhibited LTCC or RyR either before $\mathrm{MPP}^{+}$treatment or during the last 30 min of a 2-h MPP ${ }^{+}$ exposure. While preincubation with isradipine or an antagonist of RyR, 1,1'-diheptyl-4,4'-bipyridinium dibromide (DHBP), both prevented MPP ${ }^{+}$-induced elevation of $\mathrm{Ca}^{2+}$, delayed treatment was only effective when RyR but not when LTCC were inhibited (Fig. 5C). Similar responses were observed with Rhod2 (Extended Data Fig. 5-2). These data suggest that while LTCC are necessary to initiate the $\mathrm{MPP}^{+}$-mediated increase in $\mathrm{Ca}^{2+}$, they are not required once RyR are activated. In contrast, inhibition of
$\mathrm{IP}_{3}$ receptors had no effect on $\mathrm{Ca}^{2+}$ levels in $\mathrm{MPP}^{+}{ }_{-}$ treated SN neurons (Fig. 4C).

To determine the source of $\mathrm{Ca}^{2+}$ surge in $\mathrm{MPP}^{+}-$ treated neurons, we employed an adeno-associated virus that expressed a mitochondria-targeted GCaMP6m under the control of rat TH promoter, TH-2mt-GCaMP6m (Logan et al., 2014). Similar to other fluorescent probes, normalized fluorescence intensity $(470 / 410 \mathrm{~nm}$ excitation ratio) of $2 \mathrm{mt}-\mathrm{GCaMP} 6 \mathrm{~m}$ increased in SN but not VTA neurons exposed to $\mathrm{MPP}^{+}$(Fig. $5 D$ ). Importantly, this effect was blocked by an inhibitor of the mitochondrial calcium uniporter (MCU), Ru360 (Fig. 5E), suggesting that mitochondria were not the initial source of cytoplasmic $\mathrm{Ca}^{2+}$ increase, but rather accumulated it in response to changes in $\mathrm{Ca}^{2+}$ conductance at the plasma membrane or the endoplasmic reticulum (ER).

\section{Regulation of $\mathrm{DA}_{\text {cyt }}$ and $\mathrm{NO}$ by $\mathrm{Ca}^{2+}$}

To confirm that increased $\mathrm{DA}_{\text {cyt }}$ and $\mathrm{NO}$ in $\mathrm{MPP}^{+}$treated $\mathrm{SN}$ neurons result from higher $\mathrm{Ca}^{2+}$ levels in these cells, we measured these metabolites following pharmacological blockade of LTCC with dihydropyridines. Treatment of naïve $\mathrm{SN}$ cultures with nimodipine decreased $\mathrm{DA}_{\mathrm{cyt}}$ in a concentration-dependent manner (Extended Data Fig. 6-1), and the $\mathrm{IC}_{50}$ of this effect $(\sim 2.5 \mu \mathrm{M})$ was similar to that of the inhibition of the $\mathrm{Ca}_{\mathrm{v}} 1.3$ channel (Mercuri et al., 1994). Furthermore, nimodipine (5 $\mu \mathrm{M}$, 30-min preincubation) abolished the difference in $\mathrm{DA}_{\text {cyt }}$ between SN and VTA neurons both in the presence and in the absence of $\mathrm{MPP}^{+}$(Fig. 6A). Similarly, when IPE measurements were performed in cultures from the $\mathrm{Ca}_{\mathrm{v}} 1.3$ deficient mice, there was no difference in $\mathrm{DA}_{\text {cyt }}$ levels in SN and VTA neurons, either in the presence or in the absence of the toxin (Fig. 6B). In contrast, the RyR blocker DHBP had no effect on $\mathrm{DA}_{\text {cyt }}$ in $\mathrm{MPP}^{+}$-treated SN neurons (Fig. 6A).

The LTCC inhibitor (isradipine), RyR antagonists (DHBP and ruthenium red), NO synthase inhibitor (L-NAME) or an $\mathrm{MCU}$ inhibitor (Ru360) each prevented the $\mathrm{MPP}^{+}$-induced NO increase in SN neurons (Fig. 6C). The mechanism responsible for increased NO production in these cells 
A

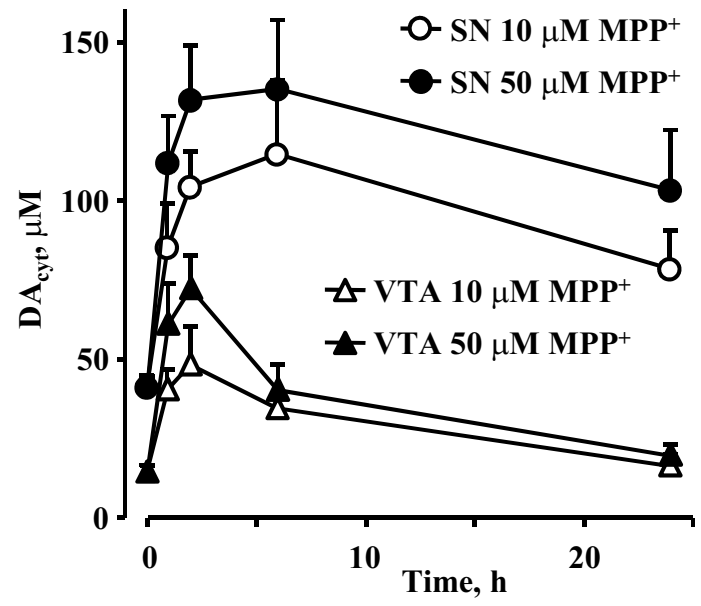

B

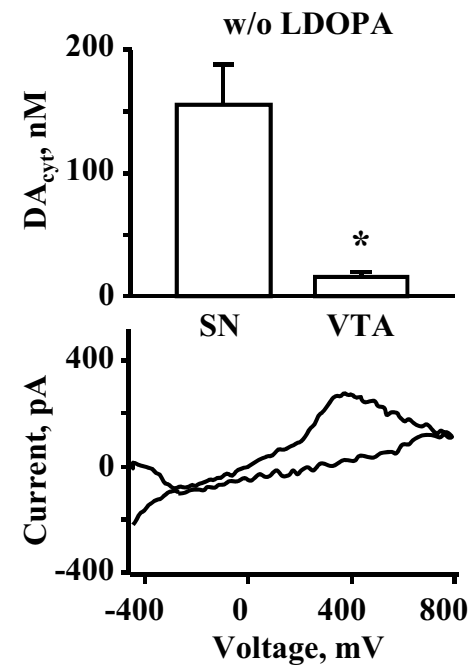

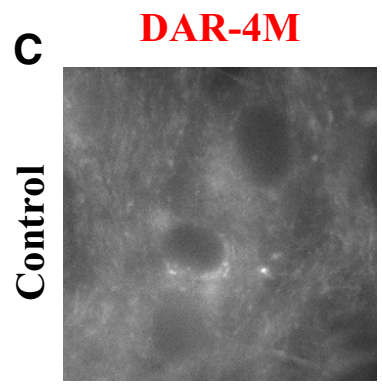

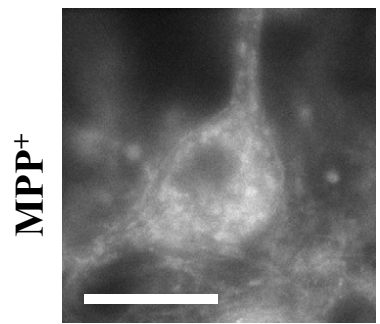

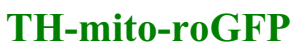
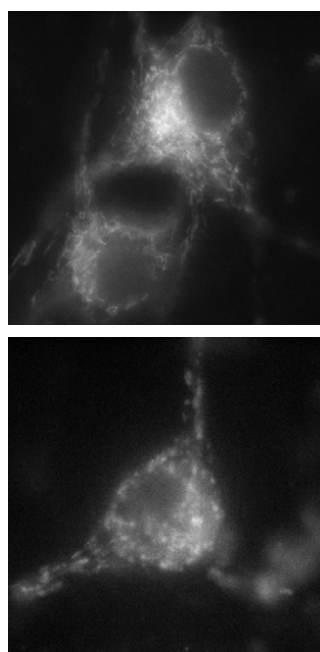
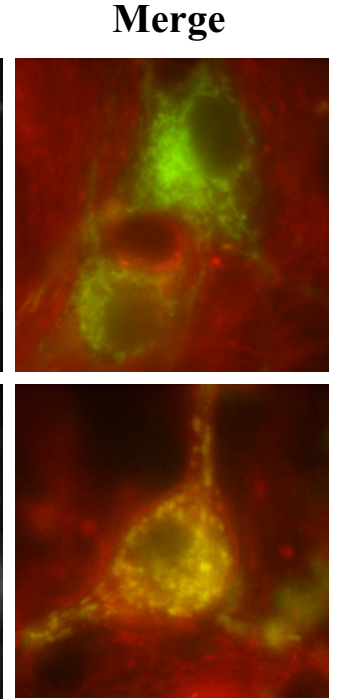

D

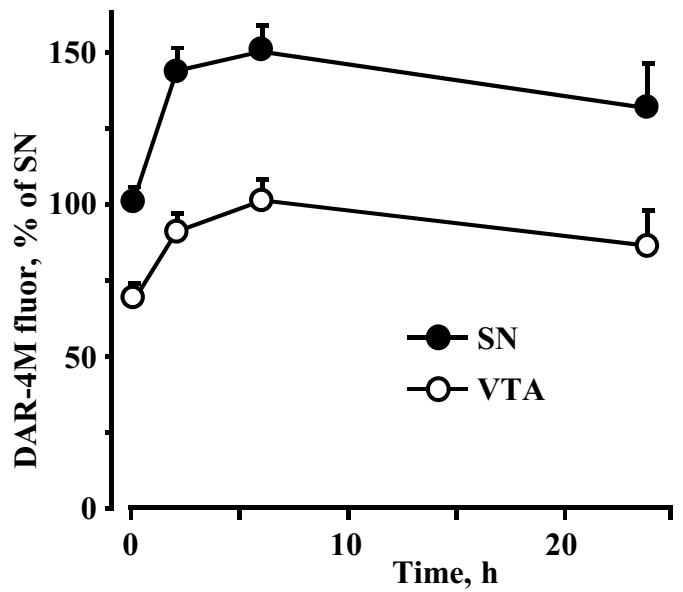

Figure 3. Effect of $\mathrm{MPP}^{+}$on $\mathrm{DA}_{\text {cyt }}$ and NO. A, Time course of changes in $\mathrm{DA}_{\text {cyt }}$ following treatment of SN or VTA neurons with 10 or $50 \mu \mathrm{M}$ $\mathrm{MPP}^{+}$. All curves are statistically different from each other by two-way ANOVA $(p<0.01 ; n=6-34$ cells from eight independent experiments). Cells were pretreated with $100 \mu \mathrm{M}$ L-DOPA for $30 \mathrm{~min}$ before the recordings. $\boldsymbol{B}$, Average DA $_{\text {cyt }}$ concentrations (top) and representative voltammogram (bottom) in SN and VTA neurons treated with $50 \mu \mathrm{M} \mathrm{MPP}^{+}$for $2 \mathrm{~h}$. No L-DOPA was added before IPE measurements. Detection threshold of IPE in CV mode is $\sim 50 \mathrm{nM} ; * p<0.01$ by $t$ test $(n=6$ and 8 cells from two independent experiments). C, Representative images of control and $\mathrm{MPP}^{+}(50 \mu \mathrm{M}$ for $2 \mathrm{~h}$ )-treated SN neurons from TH-mito-roGFP mice stained with live NO indicator DAR-4M-AM. Scale bar: $10 \mu \mathrm{m}$. $\boldsymbol{D}$, Time-dependent changes in NO concentration in SN and VTA neurons treated with $50 \mu \mathrm{M}^{\mathrm{MPP}}{ }^{+}$. DAR-4M-AM was added during the last 10 min of $\mathrm{MPP}^{+}$exposure; $p<0.001$ by two-way ANOVA ( $n=24-71$ cells from seven independent experiments).

therefore appears to involve $\mathrm{Ca}^{2+}$ entry through LTCC, followed by the activation of the RyR, and $\mathrm{Ca}^{2+}$-mediated activation of mitochondrial NOS (Fig. 2A). Additionally, DAT activity was unaffected by L-type channel blockade (Fig. $6 D$ ) and L-NAME was unable to prevent the buildup of $\mathrm{Ca}^{2+}$ in $\mathrm{MPP}^{+}$-treated SN neurons (Fig. $4 C$ ), suggesting that RyR nitrosylation and increased conductance (Kakizawa et al., 2012) did not mediate the increase of $\mathrm{Ca}^{2+}$ in toxin-exposed cells. Interestingly, neither of the above inhibitors were able to reduce $\mathrm{MPP}^{+}$-mediated increases in DAR-4M fluorescence in VTA neurons (Extended Data Fig. 6-2), suggesting that $\mathrm{MPP}^{+}$leads to an increase in NO levels independently of $\mathrm{Ca}^{2+}$ in these cells.
Rescue of neurons from MPP ${ }^{+}$-mediated mitochondria oxidation and toxicity

We next investigated the contribution of $\mathrm{DA}_{\text {cyt }}, \mathrm{Ca}^{2+}$ and $\mathrm{NO}$ in mediating mitochondrial oxidative stress in naïve and $\mathrm{MPP}^{+}$-treated $\mathrm{SN}$ neurons. Both isradipine and L-NAME decreased mito-roGFP oxidation in control SN neurons (Fig. 7A), indicating that LTCC activity and downstream up-regulation of NOS are responsible for higher basal oxidative stress in these cells. Similarly, the same inhibitors as well as RyR antagonists (DHBP and ruthenium red), each decreased mitochondrial oxidation in $\mathrm{MPP}^{+}$-treated SN neurons (Fig. 7B). Furthermore, isradipine prevented $\mathrm{MPP}^{+}$-induced changes in mitochondrial 
A
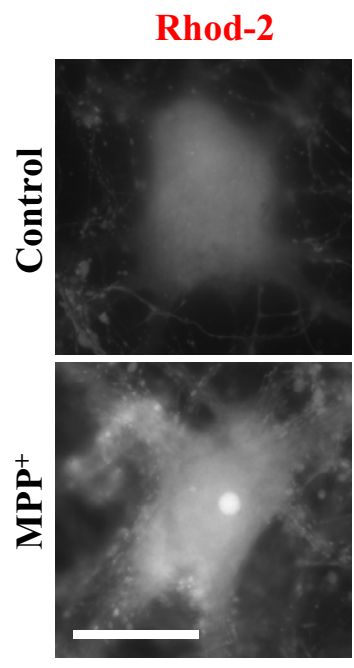

TH-mito-roGFP
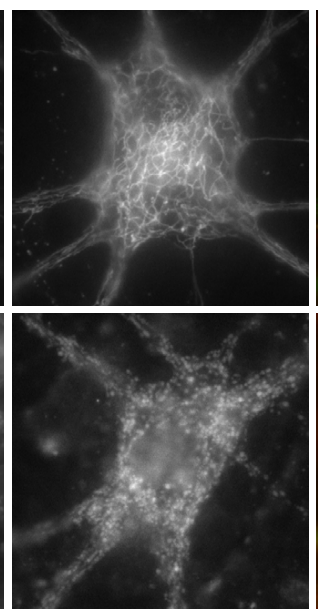

Merge
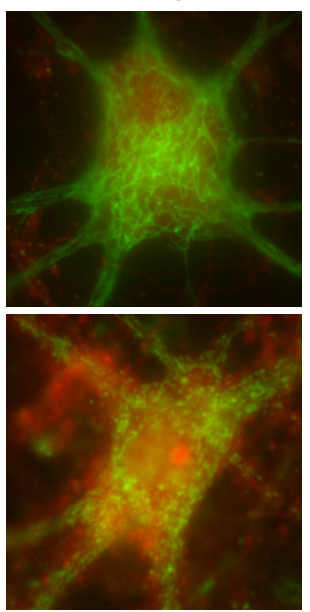

B

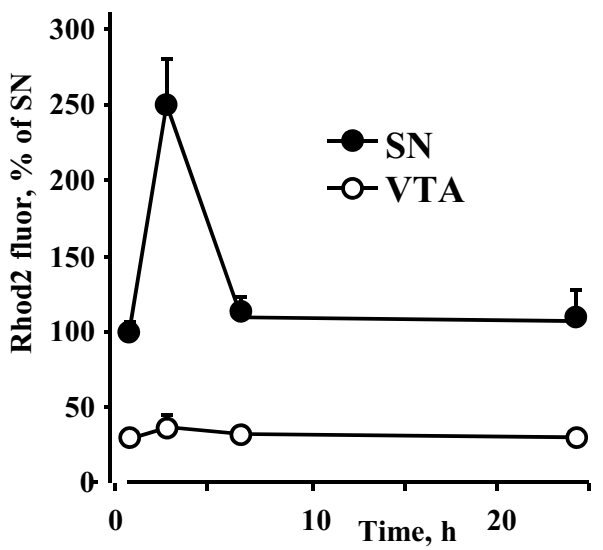

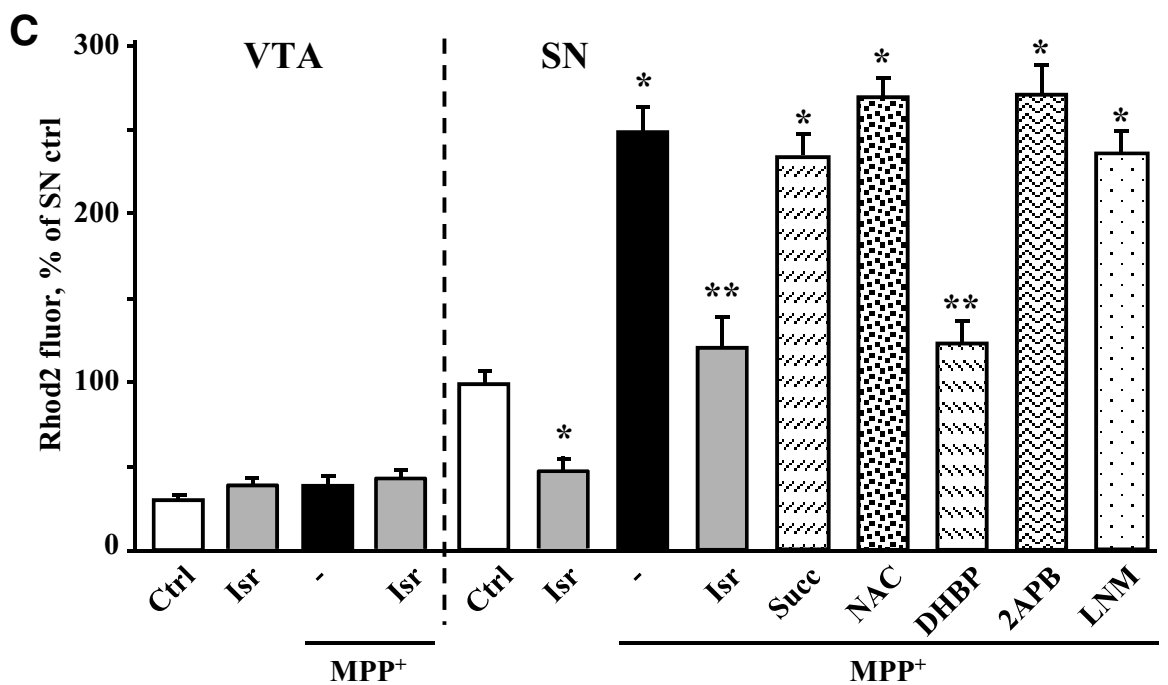

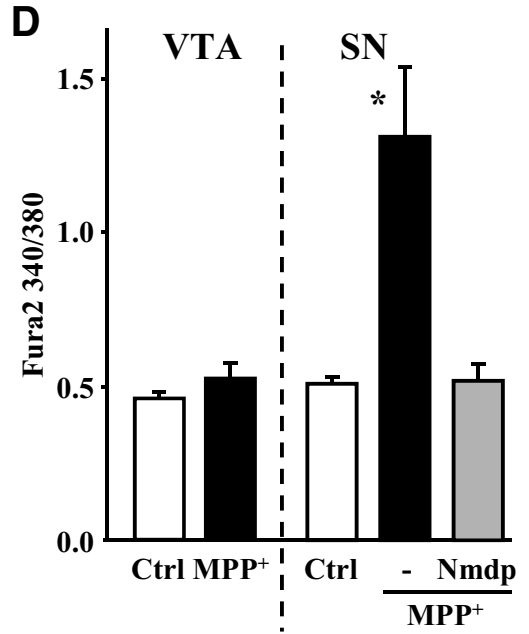

Figure 4. $\mathrm{MPP}^{+}$-induced changes in neuronal $\mathrm{Ca}^{2+}$. $\boldsymbol{A}$, Representative images of SN neurons from TH-mito-roGFP mice exposed to 50 $\mu \mathrm{M} \mathrm{MPP}{ }^{+}$for $2 \mathrm{~h}$ and stained with live $\mathrm{Ca}^{2+}$ indicator Rhod2-AM. Scale bar: $10 \mu \mathrm{m}$. No difference in intracellular fluorescence of Calcein Blue was observed between SN and VTA neurons (Extended Data Fig. 4-1). B, Time-dependent changes in $\mathrm{Ca}^{2+}$ signal in SN and VTA neurons treated with $50 \mu \mathrm{M} \mathrm{MPP}^{+}$. Rhod2-AM was always added during the last 30 min of $\mathrm{MPP}^{+}$exposure; $p<0.001$ by two-way ANOVA ( $n=9-51$ cells from four independent experiments). C. Effect of LTCC inhibitor isradipine $(5 \mu \mathrm{M})$, Complex II substrate succinate (1 mM), NOS inhibitor L-NAME (100 $\mu \mathrm{M})$, RyR blocker DHBP $(100 \mu \mathrm{M})$, or $\mathrm{IP}_{3} \mathrm{R}$ antagonist 2-APB $(50 \mu \mathrm{M})$ on $\mathrm{MPP}^{+}$-induced Ca ${ }^{2+}$ elevation in $\mathrm{SN}$ and VTA DA neurons. Cultures were preincubated with inhibitors for 30-60 min (Fig. 2, legend) and then exposed to $50 \mu \mathrm{M}$ MPP ${ }^{+}$for 2 h; $p<0.01$ from corresponding control (*; white bars) or MPP ${ }^{+}(* *)$ by one-way ANOVA with Tukey's post hoc test $(n=11-100$ cells from 14 independent experiments). $\boldsymbol{D}$, Fluorescence intensity ratios at 340 and $380 \mathrm{~nm}$ excitation and $510 \mathrm{~nm}$ emission of fura-2 AM-treated SN and VTA neurons from TH-GFP mice exposed to $50 \mu \mathrm{M} \mathrm{MPP}^{+}$for $2 \mathrm{~h}$. LTCC inhibitor nimodipine (5 $\left.\mu \mathrm{M}\right)$ was added 30 min before the toxin; $* p<0.05$ from all other groups by one-way ANOVA with Tukey's post hoc test ( $n=37-68$ cells from three independent experiments).

morphology (Fig. 7C), highlighting the importance of $\mathrm{Ca}^{2+}$ in mediating the stress following toxin exposure. Blockade of DA synthesis with Bsrz had no effect on the oxidation of mitochondria in control SN neurons, but significantly decreased it in cells treated with $\mathrm{MPP}^{+}$, confirming a role for DA in mediating $\mathrm{MPP}^{+}$-induced oxidative stress (Fig. $7 A, B$ ). In contrast, the VMAT inhibitor reserpine had no significant effect, arguing against a possibility that DA released from synaptic vesicles is the source of oxidative stress in the soma of $\mathrm{MPP}^{+}$-treated neurons. Finally, restoring ETC function with succinate showed a trend for decreased mitochondrial oxidative stress in toxin-treated SN neurons, but the effect did not reach statistical significance (Fig. 7B).

As our data point to LTCC as important mediators of alterations in $\mathrm{DA}_{\text {cyt }}$ and $\mathrm{NO}$ in $\mathrm{MPP}^{+}$-treated neurons, we investigated whether pharmacological blockade of these channels is neuroprotective against the toxin, as reported for dihydropyridines in vivo (Chan et al., 2007). Nimodipine had no effect on the survival of VTA neurons exposed to $\mathrm{MPP}^{+}$, but provided a partial rescue to $\mathrm{SN}$ neurons, equalizing the difference in $\mathrm{MPP}^{+}$-induced toxicity between the two neuronal types (Fig. 7D). While DHBP was cytotoxic to midbrain cultures, blockade of RyR with ru- 
A

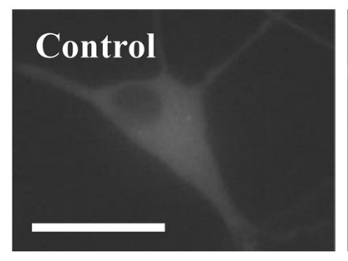

SN

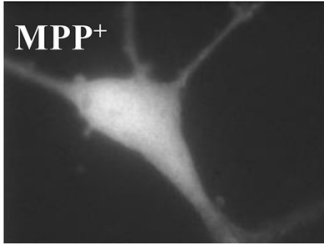

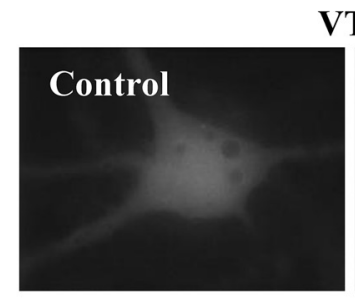

VTA

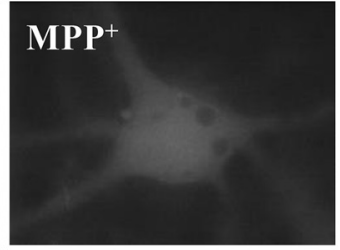

B

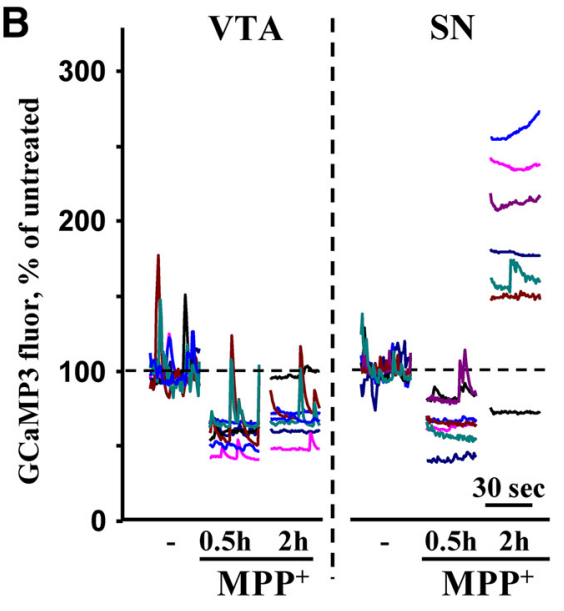

C

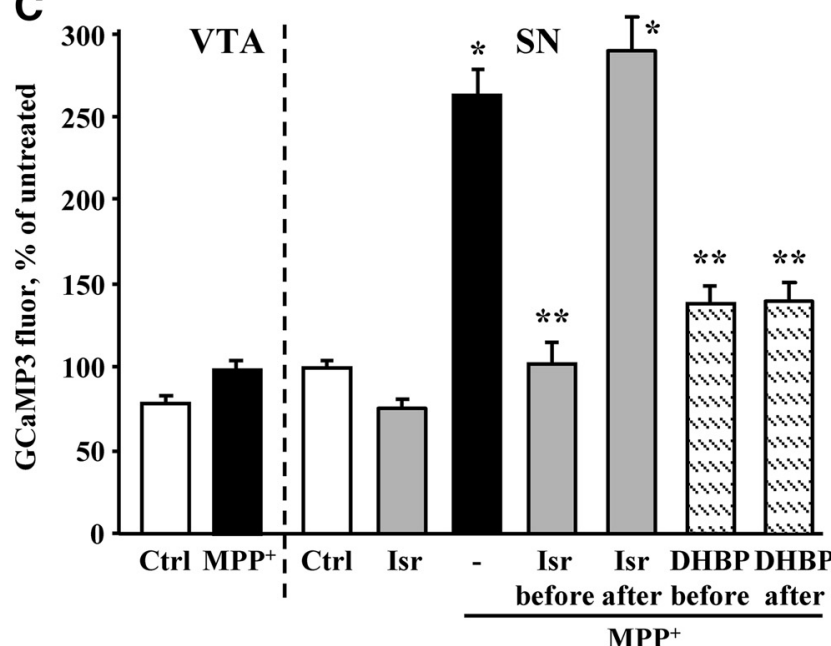

D

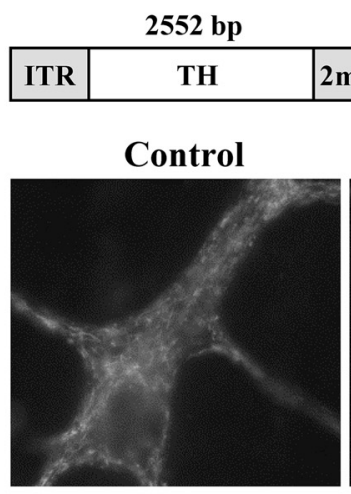

1558 bp 2mt-GCaMP6m Sv40

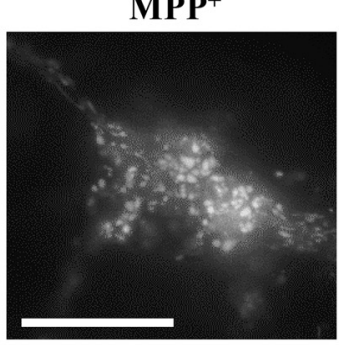

$\mathbf{E}$

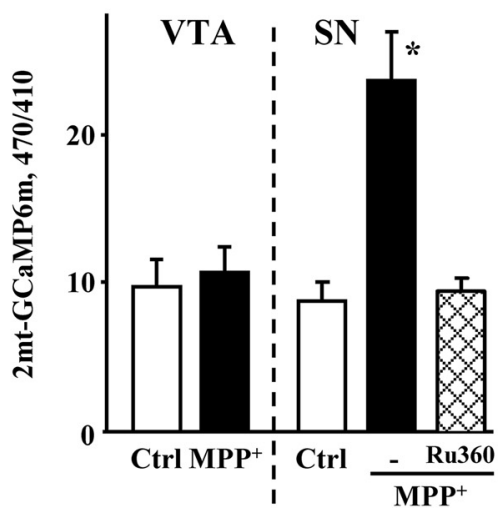

Figure 5. Changes in cytosolic and mitochondrial $\mathrm{Ca}^{2+} \cdot \boldsymbol{A}$, Representative live images of SN and VTA neurons from DAT-GCaMP3 mice exposed to $50 \mu \mathrm{M} \mathrm{MPP}^{+}$for $2 \mathrm{~h}$. Scale bar: $10 \mu \mathrm{m}$. B. Examples of live GCaMP3 recordings from MPP ${ }^{+}$-treated SN and VTA neurons. At 0, 30, and 120 min of toxin exposure, a series of 50 images at $2 \mathrm{~Hz}$ frequency was taken from the same cells. See Extended Data Figure 5-1A for an example of untreated cells and Extended Data Figure 5-1B for the analysis of the SD of each 30-s recording. Recordings were done at $37^{\circ} \mathrm{C}$. C, Changes in GCaMP3 fluorescence intensity in the cell bodies of VTA and SN neurons exposed to $\mathrm{MPP}^{+}(50 \mu \mathrm{M}, 2 \mathrm{~h})$ in the presence or in the absence of $5 \mu \mathrm{M}$ isradipine or $100 \mu \mathrm{M}$ DHBP (see Extended Data Fig. 5-1C for the effect of isradipine in VTA DA neurons). The blockers were added either 30 min before MPP ${ }^{+}$or during the last 30 min of toxin exposure; $p<0.01$ from control $(*)$ or $\mathrm{MPP}^{+}(* *)$ by one-way ANOVA with Tukey's post hoc test $(n=20-75$ cells from eight independent experiments). Extended Data Figure 5-2 shows analysis of Rhod2 fluorescence in SN neurons treated with isradipine, DHBP, and $\mathrm{MPP}^{+}$the same way. $\boldsymbol{D}$, Schematics of the TH-2mt-GCaMP6m vector and representative images of untreated and $\mathrm{MPP}^{+}$-treated SN neurons infected with AAV9-TH-2mt-GCaMP6m. ITR, inverted terminal repeat; TH, rat tyrosine hydroxylase promoter. $\boldsymbol{E}$, Ratio of background-subtracted fluorescence intensities (410 and $470 \mathrm{~nm}$ excitation, $535 \mathrm{~nm}$ emission) of the mitochondria in SN and VTA neurons expressing 2mt-GCaMP6m; $* p<0.01$ from all other groups by one-way ANOVA with Tukey's post hoc test ( $n=18-29$ cells from three independent experiments).

thenium red or MCU with Ru360 each significantly increased the survival of SN but not VTA DA neurons (Fig. 7D).

To further investigate the mechanism of toxicity, we measured the level of ER stress by determining the intracellular localization of activating transcription factor 6
(ATF6). ER stress induced by $\mathrm{Ca}^{2+}$ store depletion leads to the proteolytic cleavage of ATF6 followed by the translocation of its cytosolic portion to the nucleus, where it acts as a transcription factor to upregulate expression of ER chaperones. We observed a significant increase in the 

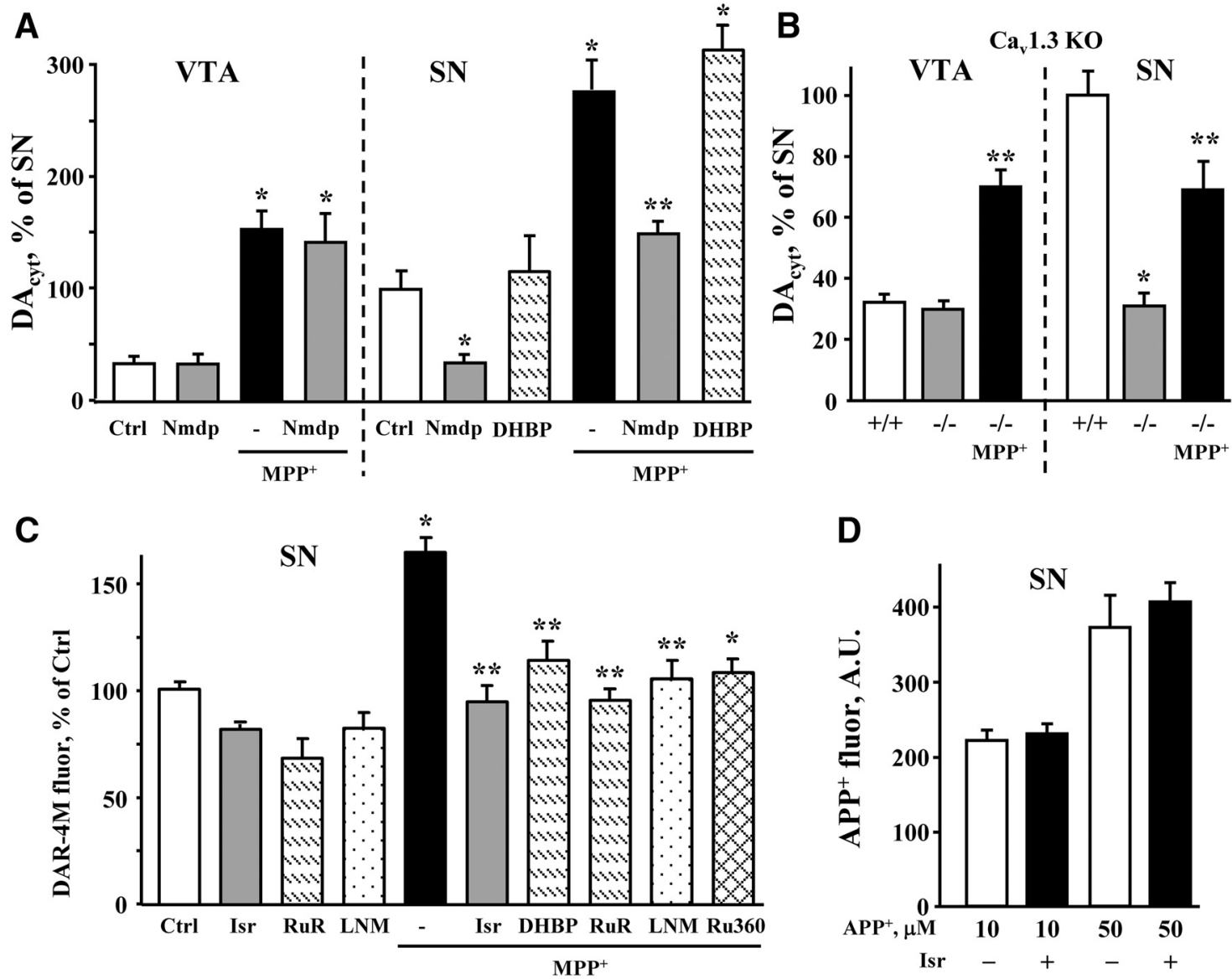

Figure 6. Dependence of $\mathrm{DA}_{\text {cyt }}$ and NO on intracellular $\mathrm{Ca}^{2+}$ levels. $\boldsymbol{A}$, Changes in $\mathrm{DA}_{\mathrm{cyt}}$ in $\mathrm{SN}$ and VTA neurons exposed to $50 \mu \mathrm{M}$ MPP for $2 \mathrm{~h}$ in the presence and in the absence of nimodipine $(5 \mu \mathrm{M})$ or DHBP $(100 \mu \mathrm{M})$ added 30 min before $\mathrm{MPP}^{+} ; p<0.01$ from corresponding control (*) or $\mathrm{MPP}^{+}$-treated (**) neurons by one-way ANOVA with Tukey's post hoc test $(n=9-28$ cells from four independent experiments). Incubations with all drugs were done at $37^{\circ} \mathrm{C}$, followed by imaging at RT. Dependence of DA cyt $_{\text {on nimodipine }}$ concentration in naïve SN cultures is shown of Extended Data Figure 6-1. B, DA cyt $_{\text {t }}$ levels in SN and VTA neurons from WT (+/+) and Ca 1.3 knock out (-/-) mice; $p<0.01$ from corresponding $+/+(*)$ or both $+/+$ and -/- groups (**) by one-way ANOVA with Tukey's post hoc test ( $n=20-64$ cells from seven independent experiments). $\boldsymbol{C}$, Normalized fluorescence intensity of NO indicator DAR-4M in SN neurons pretreated with indicated inhibitors and then exposed to $50 \mu \mathrm{M} \mathrm{MPP}^{+}$for $2 \mathrm{~h} ; p<0.001$ from control $(*)$ or MPP $^{+}(* *)$ groups by one-way ANOVA with Tukey's post hoc test ( $n=15-80$ cells from 14 independent experiments). Quantification of DAR-4M fluorescence in VTA neurons treated with some of the same drugs is shown in Extended Data Figure 6-2. D. Fluorescence intensity in the somas of SN and VTA neurons treated with 10 or $50 \mu \mathrm{M} \mathrm{APP}{ }^{+}$for $10 \mathrm{~min}$ in the presence and the absence of $5 \mu \mathrm{M}$ isradipine (30-min preincubation). $N=16-20$ cells.

nuclear to cytosolic ratio of ATF6 immunofluorescent label after $24 \mathrm{~h}$ of SN neurons exposure to $\mathrm{MPP}^{+}$(Fig. 7E). Furthermore, in support of the observation that $\mathrm{ER} \mathrm{Ca}^{2+}$ store depletion is secondary to LTCC opening, pretreatment with isradipine prevented $\mathrm{MPP}^{+}$-induced changes in ATF6 localization in SN but not VTA neurons (Fig. 7F).

Several experiments described above demonstrate that dihydropyridines counter changes in $\mathrm{Ca}^{2+}, \mathrm{DA}_{\text {cyt }}$ and $\mathrm{NO}$ in $\mathrm{SN}$ neurons, lowering the levels of these metabolites to those in VTA neurons. We therefore investigated if LTCC blockade also negates the difference in the contribution of various toxicity pathways in $\mathrm{MPP}^{+}$-treated SN and VTA neurons. Indeed, the difference in the neuroprotective potency of Bsrz, succinate and L-NAME in SN and VTA neurons (Fig. 2B) disappeared when SN neurons were pretreated with isradipine (Fig. $7 G$ ). We note that in contrast to complete neuroprotection of VTA neurons from
$\mathrm{MPP}^{+}$toxicity by succinate and L-NAME, there was only a partial rescue of isradipine-treated SN neurons with these inhibitors either alone or in combination. Thus, additional differences between the two neuronal populations, such as higher activity of DAT-mediated uptake of $\mathrm{MPP}^{+}$in SN neurons (Fig. $1 D-F$ ) that was insensitive to dihydropyridine treatment (Fig. 6D), or the extensive arborization of cultured SN neurons (Pacelli et al., 2015) also played a role. Remarkably, isradipine also provided partial protection to SN, but not VTA neurons from piericidin A toxicity, demonstrating that $\mathrm{Ca}^{2+}$ influx via the LTCC is an important contributor to the sensitivity of $\mathrm{SN}$ neurons to mitochondrial stress such as Complex I inhibition (Fig. 7H).

\section{Role of aSyn in MPP ${ }^{+}$-mediated toxicity}

Finally, we examined whether expression of aSyn was required for selective $\mathrm{MPP}^{+}$neurotoxicity. aSyn is a major 

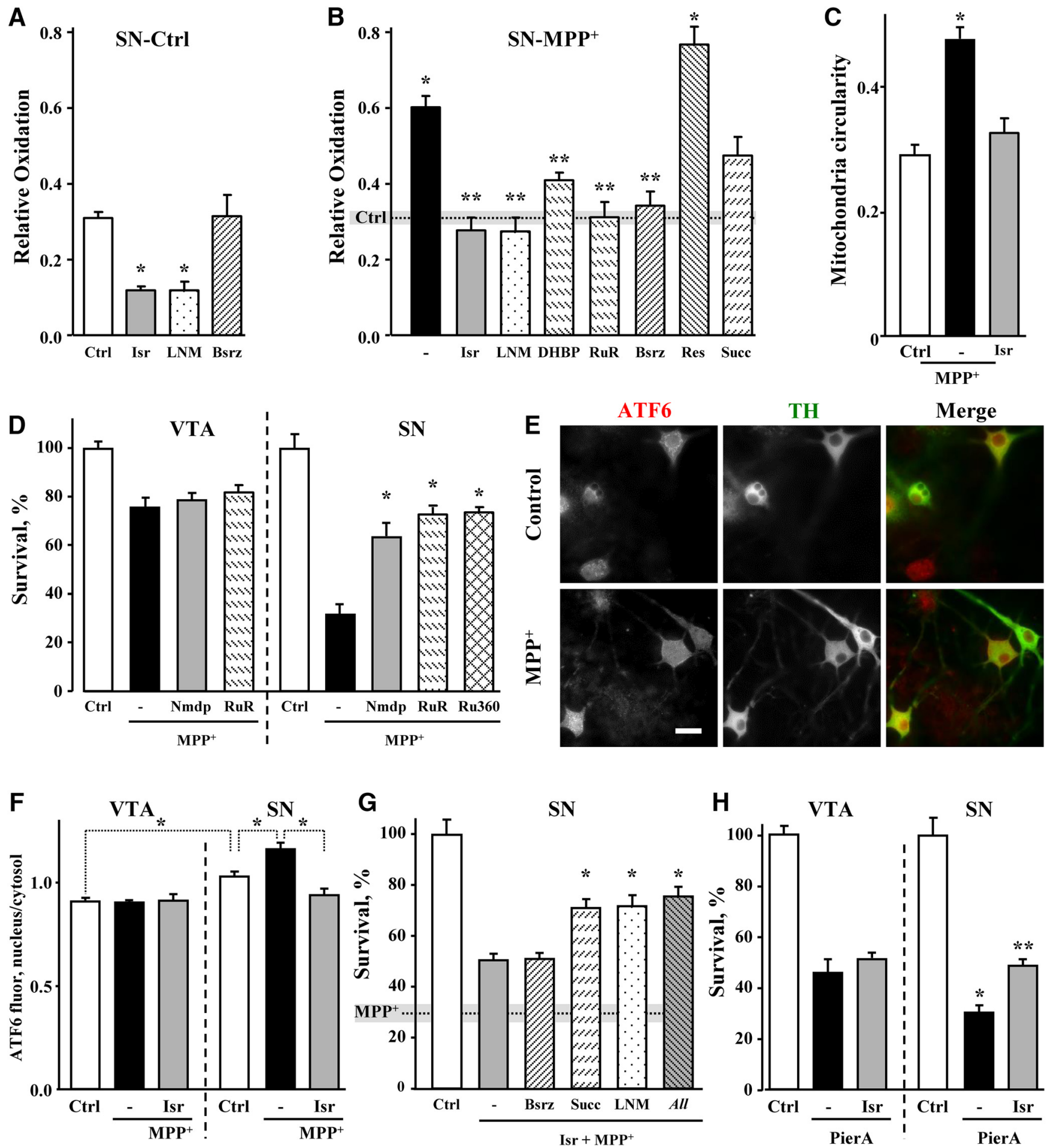

Figure 7. Rescue of DA neurons from $\mathrm{MPP}^{+}$-induced mitochondrial oxidation and toxicity. $\boldsymbol{A}, \boldsymbol{B}$, Relative oxidation of cultured $\mathrm{SN}$ neurons from TH-mito-roGFP mice in the absence $(\boldsymbol{A})$ and in the presence $(\boldsymbol{B})$ of $50 \mu \mathrm{M} \mathrm{MPP}^{+}$for $2 \mathrm{~h}$. Neurons were preincubated with metabolic effectors as indicated in the text and Figure $2 A$, legend; $p<0.001$ from control (*) or MPP ${ }^{+}(* *)$ by one-way ANOVA with Tukey's post hoc test ( $n=12-44$ cells from 20 independent experiments). $\boldsymbol{C}$, Rescue of mitochondria morphology in SN neurons treated with $50 \mu \mathrm{M} \mathrm{MPP}^{+}$for $2 \mathrm{~h}$ in the presence of $5 \mu \mathrm{M}$ isradipine (30-min preincubation); $* p<0.05$ from untreated cells by one-way ANOVA with Tukey's post hoc test ( $n=14-23$ cells from three independent experiments). $\boldsymbol{D}$, MPP $^{+}$-mediated toxicity in cultures pretreated with nimodipine $(5 \mu \mathrm{M})$, ruthenium red $(20 \mu \mathrm{M})$ or Ru360 $(10 \mu \mathrm{M})$. None of the drugs were toxic to DA neurons in the absence of $\mathrm{MPP}^{+} ; * p<0.001$ from both control and MPP ${ }^{+}$by one-way ANOVA with Tukey's post hoc test $(n=3-23$ dishes from seven independent experiments). $\boldsymbol{E}$, Representative images of SN neurons immunostained for TH and ATF6. Scale bar: $10 \mu \mathrm{m}$. $\boldsymbol{F}$, Quantification of the ratios of nuclear to cytosolic (perinuclear) ATF6 fluorescence in SN and VTA neurons treated with MPP ${ }^{+}$for 24 h. Isradipine was added 30 min before $\mathrm{MPP}^{+} ; * p<0.001$ from control SN neurons by one-way ANOVA with Tukey's post hoc test 
continued

( $n=16-26$ cells from two independent experiments). $\mathbf{G}$, Toxicity in SN cultures treated with both isradipine and MPP ${ }^{+}$. Dotted line and gray bar represent the level of survival (mean \pm SEM) of SN neurons treated with MPP ${ }^{+}$only. In the presence of the LTCC blocker, the sensitivity of SN neurons to different metabolic effectors became similar to that of VTA neurons (compare to Fig. 2B). Note, however, that none of the inhibitors combinations provided complete rescue of SN neurons from neurotoxicity. "All" designates a group pretreated with isradipine, Bsrz, succinate, and L-NAME simultaneously; $* p<0.01$ from both control and MPP ${ }^{+}$by one-way ANOVA with Tukey's post hoc test ( $n=6-28$ dishes from 13 independent experiments). $\boldsymbol{H}$, Effect of the LTCC blockade on the survival of pierecidin A-treated SN and VTA neurons; $p<0.001$ from control (*) or pierecidin A (**) by one-way ANOVA with Tukey's post hoc test ( $n=7-13$ cells from four independent experiments).

component of Lewy bodies, a pathologic hallmark of PD, and is implicated in the pathology of the disease as mutations or overexpression of aSyn give rise to a dominant form of PD. Conversely, deletion of aSyn is protective in the MPTP mouse model of PD (Dauer et al., 2002), although the mechanism of neuroprotection is unknown. We found that, similar to in vivo reports, both SN and VTA neurons from aSyn-deficient mice (aSyn $\mathrm{KO}$ ) were more resistant to $\mathrm{MPP}^{+}$-induced toxicity than neurons from WT animals (Fig. 8A,B).

Whereas DAT-mediated uptake (Fig. $8 C$ ) and DA cyt $_{\text {lev- }}$ els (Mosharov et al., 2009) were unaffected by aSyn deletion, we observed no detectable $\mathrm{Ca}^{2+}$ increase in $\mathrm{SN}$ neurons following $\mathrm{MPP}^{+}$treatment (Fig. $8 D$ ). Similarly, no
A

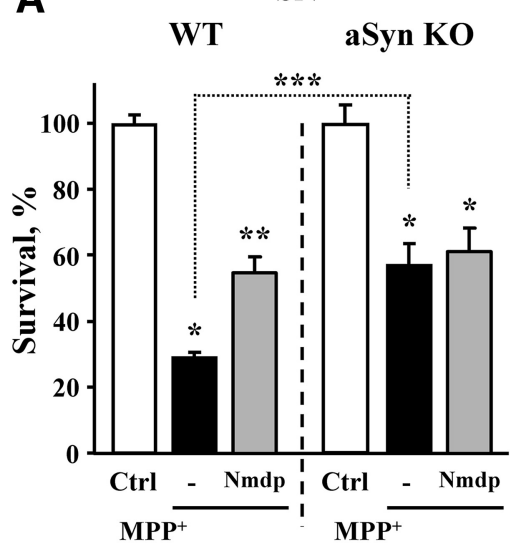

D

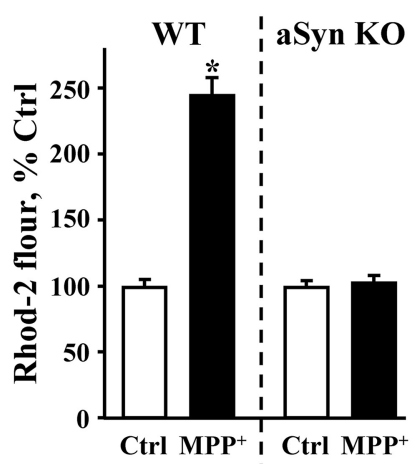

B

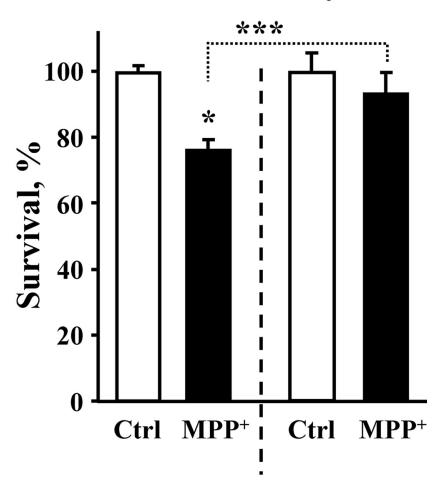

C

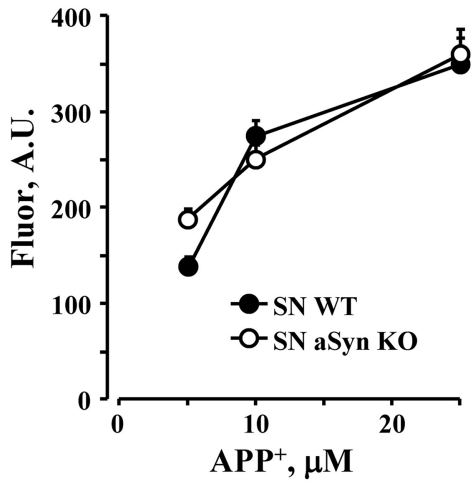

$\mathbf{E}$

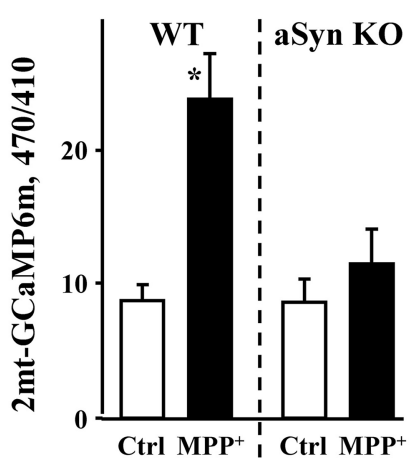

$\mathbf{F}$

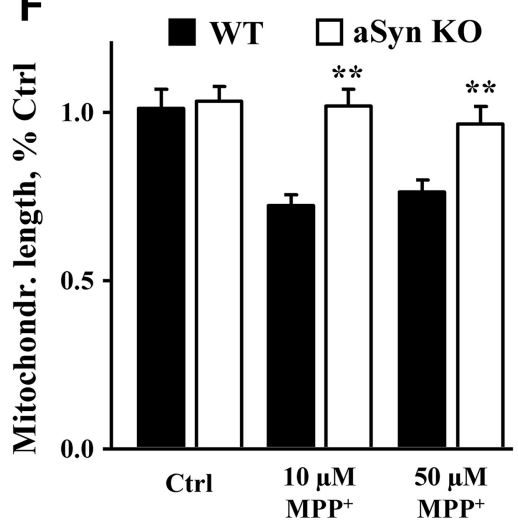

Figure 8. Rescue of $\mathrm{MPP}^{+}$-treated SN neurons by aSyn deletion. $\boldsymbol{A}$, Toxicity in SN cultures from WT and aSyn null mice treated with nimodipine and $\mathrm{MPP}^{+} ; p<0.001$ from corresponding control $(*)$, both corresponding control and $\mathrm{MPP}^{+}(* *)$ or WT and aSyn $\mathrm{KO}$ MPP $^{+}$-treated groups $(* * *)$ by one-way ANOVA with Tukey's post hoc test ( $n=6-16$ dishes from three independent experiments). $\boldsymbol{B}$, Effect of aSyn deletion on MPP ${ }^{+}$-mediated toxicity in VTA DA cultures; $p<0.01$ from corresponding control (*) or WT and aSyn KO MPP ${ }^{+}$-treated groups (***) by one-way ANOVA with Tukey's post hoc test $(n=6-23$ dishes from two independent experiments). $\boldsymbol{C}$, DAT-mediated uptake of $\mathrm{APP}^{+}$is unchanged in aSyn-deficient SN neurons ( $n=16-24$ cells from two independent experiments). $\boldsymbol{D}, \mathrm{MPP}^{+}$does not induce $\mathrm{Ca}^{2+}$ surge in SN neurons from aSyn null mice. WT and sSyn KO SN neurons were treated with $50 \mu \mathrm{M}$ $\mathrm{MPP}^{+}$for $2 \mathrm{~h}$ and changes in $\mathrm{Ca}^{2+}$ were accessed with Rhod2 $(n=41-124$ neurons from five independent experiments). $\boldsymbol{E}$, Deletion of aSyn prevented the increase in mitochondrial $\mathrm{Ca}^{2+}$ in $\mathrm{MPP}^{+}$-treated SN neurons $(n=18-26$ neurons from three independent experiments). $\boldsymbol{F}$, Mitochondria morphology did not change significantly in toxin-exposed SN neurons from aSyn null mice $(n=7-15$ neurons from three independent experiments). 
effect of the toxin on mitochondrial $\mathrm{Ca}^{2+}$ (Fig. 8E) or morphology (Fig. 8F) were seen in aSyn KO neurons. These results suggest that the neuroprotection in the absence of aSyn involves a decrease in the $\mathrm{MPP}^{+}$induced surge of $\mathrm{Ca}^{2+}$. Consistently, the effects of aSyn deletion and L-type channels blockade on neuronal survival were not additive (Fig. $8 A$ ).

As aSyn deletion provided such a strong effect on cell survival and $\mathrm{Ca}^{2+}$ levels in MPP ${ }^{+}$-treated SN neurons, we wondered if the reason that VTA neurons are more resistant to $\mathrm{MPP}^{+}$is because of lower expression of aSyn. We thus compared aSyn levels in SN and VTA DA neurons by quantitative immunofluorescence. In WT DA neurons, we observed both cytosolic and nuclear aSyn staining that was absent in aSyn KO cultures (Fig. 9A), suggesting that aSyn may indeed be present in the nucleus as originally reported (Maroteaux et al., 1988). Comparison of fluorescence intensity in the cytosol of SN and VTA neurons from WT mice showed $\sim 10 \%$ higher aSyn expression in SN than VTA neurons (Fig. 9B), although the difference did not reach statistical significance.

We then addressed whether aSyn overexpression could potentiate $\mathrm{MPP}^{+}$-induced $\mathrm{Ca}^{2+}$ influx through the LTCC. We infected SN and VTA cultures from DATGCaMP3 mice either with an adeno-associated virus overexpressing human WT aSyn (hWT) or a red fluorescent protein mKate2 as control. Five days after infection, this produced robust overexpression of aSyn, reaching $\sim 5$-fold increase in both SN and VTA neurons (Fig. 9C). While control or hWT aSyn viruses had no effect on GCaMP3 fluorescence in untreated cells, aSyn overexpression exacerbated the MPP ${ }^{+}$-induced $\mathrm{Ca}^{2+}$ increase in $\mathrm{SN}$ neurons (Fig. 9D). Furthermore, the toxin-induced $\mathrm{Ca}^{2+}$ increase was completely occluded by LTCC blockade with isradipine regardless of aSyn overexpression. In stark contrast to $\mathrm{SN}$ neurons, aSyn overexpression did not sensitize VTA neurons to MPP ${ }^{+}$, as GCaMP3 fluorescence was identical in untreated and $\mathrm{MPP}^{+}$-treated VTA neurons infected with either control or hWT viruses. Isradipine, similarly, had no effect on GCaMP3 fluorescence in VTA cultures (Fig. 9E).

\section{Discussion}

Environmental neurotoxins such as MPTP and rotenone are widely used to induce selective degeneration of SN neurons in vivo and in vitro and mimic pathology in idiopathic PD, although the mechanisms responsible for this selectivity remain controversial (Hasbani et al., 2005; Jackson-Lewis and Smeyne, 2005; Choi et al., 2008). Perhaps the most prominent candidate for selective neurotoxicity has been higher DAT activity in SN neurons, but our data argue against this being the sole reason. First, while DAT-mediated uptake of $\mathrm{MPP}^{+}$was indeed $\sim 40 \%$ greater in SN than VTA neurons, there were $60-70 \%$ higher levels and a different time course of toxicity in SN cultures (Fig. $1 A, B$ ). Second, the $I_{50}$ of nomifensinemediated rescue of $\mathrm{SN}$ neurons from $\mathrm{MPP}^{+}$was $\sim 8$-fold higher than the $\mathrm{IC}_{50}$ of nomifensine-mediated blockade of DAT. Finally, pharmacological blockade of LTCC, which had no effect on DAT activity, abolished $\mathrm{MPP}^{+}$-induced metabolic differences between SN and VTA neurons and provided protection selectively to $\mathrm{SN}$ neurons. While the difference in DAT activity appears to play a minor role, we found that several key metabolic players, including $\mathrm{Ca}^{2+}$, $\mathrm{DA}, \mathrm{NO}$, and aSyn underlie the higher sensitivity of SN neurons to MPP ${ }^{+}$.

$\mathrm{Ca}_{\mathrm{v}} 1.3 \mathrm{LTCC}$ provide pacemaking activity in $\mathrm{SN}$ and LC neurons and it has been postulated that elevated cytoplasmic $\mathrm{Ca}^{2+}$ provides an energy load, leading to "wear and tear" of cellular homeostatic machinery (Surmeier, 2007). Furthermore, pharmacological blockade of the LTCC is neuroprotective against systemic MPTP administration in vivo (Kupsch et al., 1996; Chan et al., 2007). To investigate the role of $\mathrm{Ca}^{2+}$ in mediating the toxicity of $\mathrm{MPP}^{+}$, we employed several optical probes. Following the initial decrease in $\mathrm{Ca}^{2+}$ that was consistent with $\mathrm{MPP}^{+}$mediated activation of $\mathrm{K}_{\mathrm{ATP}}$ and Girk2 channels (Chung et al., 2005; Liss et al., 2005; Lüscher and Slesinger, 2010; Yee et al., 2014), we found that after 2-3h of exposure, cellular $\mathrm{Ca}^{2+}$ increased transiently and selectively in $\mathrm{SN}$ neurons by a mechanism that involved the activity of L-type channels and RyR, but not the $\mathrm{IP}_{3}$ receptors. As mitochondrial and cytoplasmic $\mathrm{Ca}^{2+}$ appeared to rise in parallel in toxin-treated neurons, the source of the $\mathrm{Ca}^{2+}$ surge likely involved an increase in plasma membrane or ER conductance, followed by mitochondrial uptake via MCU. Our data implicate the involvement of L-type channels during the initial increase in $\mathrm{Ca}^{2+}$, permitting the opening of the RyR to produce still higher toxin-induced $\mathrm{Ca}^{2+}$ elevation.

It is unknown whether and to what degree the membrane of DA neurons is permeable to the Complex II precursor succinate. It has, however, been recently demonstrated that cortical neurons express the $\mathrm{Na}^{+}$-coupled carboxylate transporter 2 and are able to accumulate $\left[{ }^{14} \mathrm{C}\right]$ succinate with an affinity and $\mathrm{V}_{\max }$ of $7.3 \pm 1.6 \mu \mathrm{M}$ and $266.4 \pm 15.2 \mathrm{pmol} / \mathrm{mg}$ protein/h, respectively (Yodoya et al., 2006). Here, we show that succinate did not prevent the buildup of $\mathrm{Ca}^{2+}$ and provided no rescue to $\mathrm{MPP}^{+}$-treated SN neurons, but enhanced the survival of VTA neurons (Fig. 2B) or isradipine-pretreated SN neurons (Fig. 7G), suggesting that ATP depletion was not the initial cause of biochemical changes that led to toxicity. Consistently, the glutathione precursor, NAC, rescued SN neurons (Fig. 2B) without affecting the $\mathrm{MPP}^{+}$-induced increase in $\mathrm{Ca}^{2+}$ (Fig. 4C), indicating that the $\mathrm{Ca}^{2+}$ increase preceded rather than followed cellular oxidative stress. Interestingly, selective Complex I blockade by piericidin A also produced higher toxicity in SN than VTA DA neurons (Fig. 2C) and, similar to $\mathrm{MPP}^{+}$effects, this difference was negated by pretreatment with the LTCC inhibitor (Fig. 7H). This again suggests that ETC inhibition is an additive factor, rather than the source of all metabolic changes that follow.

The contribution of DA homeostasis to MPTP-induced toxicity has been controversial. Disruption of DA vesicular storage and inhibition of MAO by MPP ${ }^{+}$lead to the accumulation of $\mathrm{DA}_{\mathrm{cyt}}$, oxidative stress and cell death in midbrain cultures (Lotharius et al., 1999; Choi et al., 2015). However, $\mathrm{SN}$ neurons in animals that lack TH and therefore are unable 
A
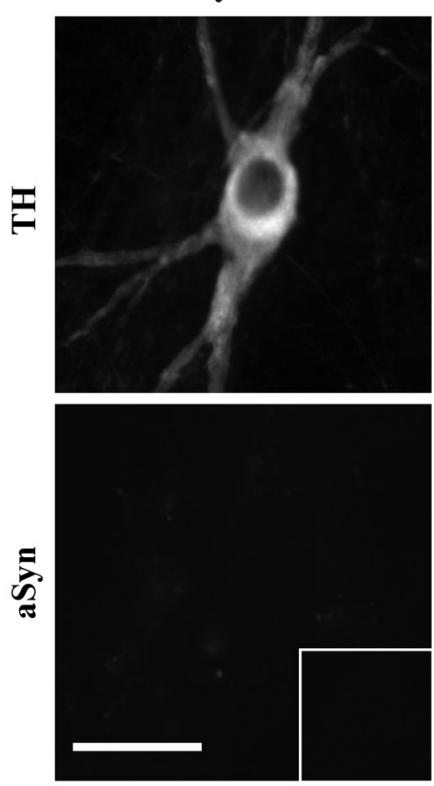

WT
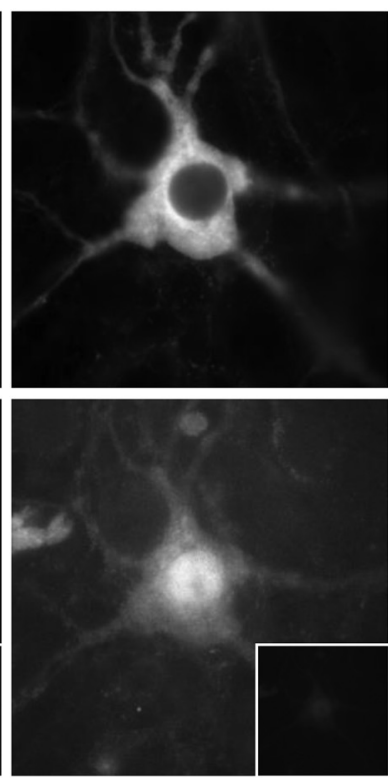

AAV-aSyn
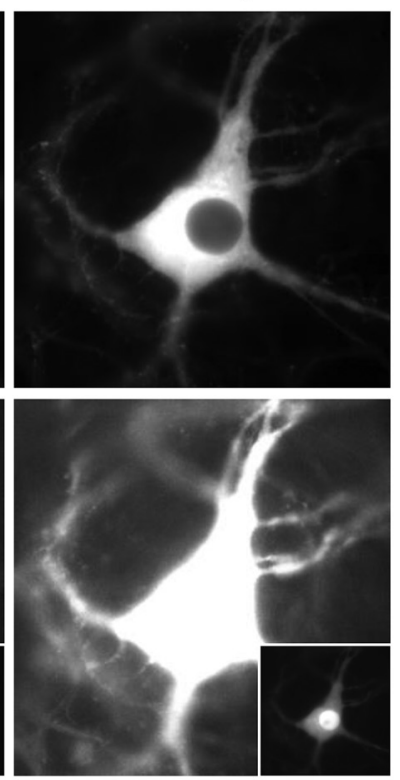

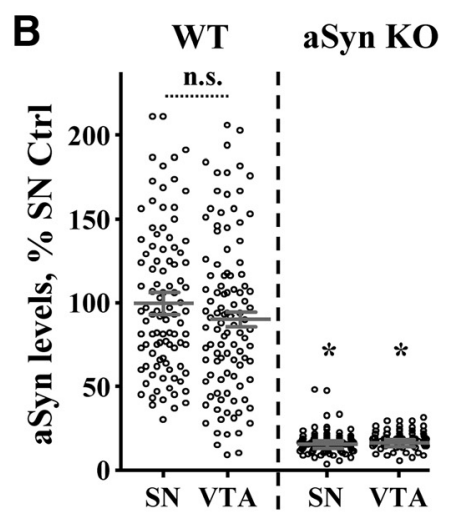

D

SN
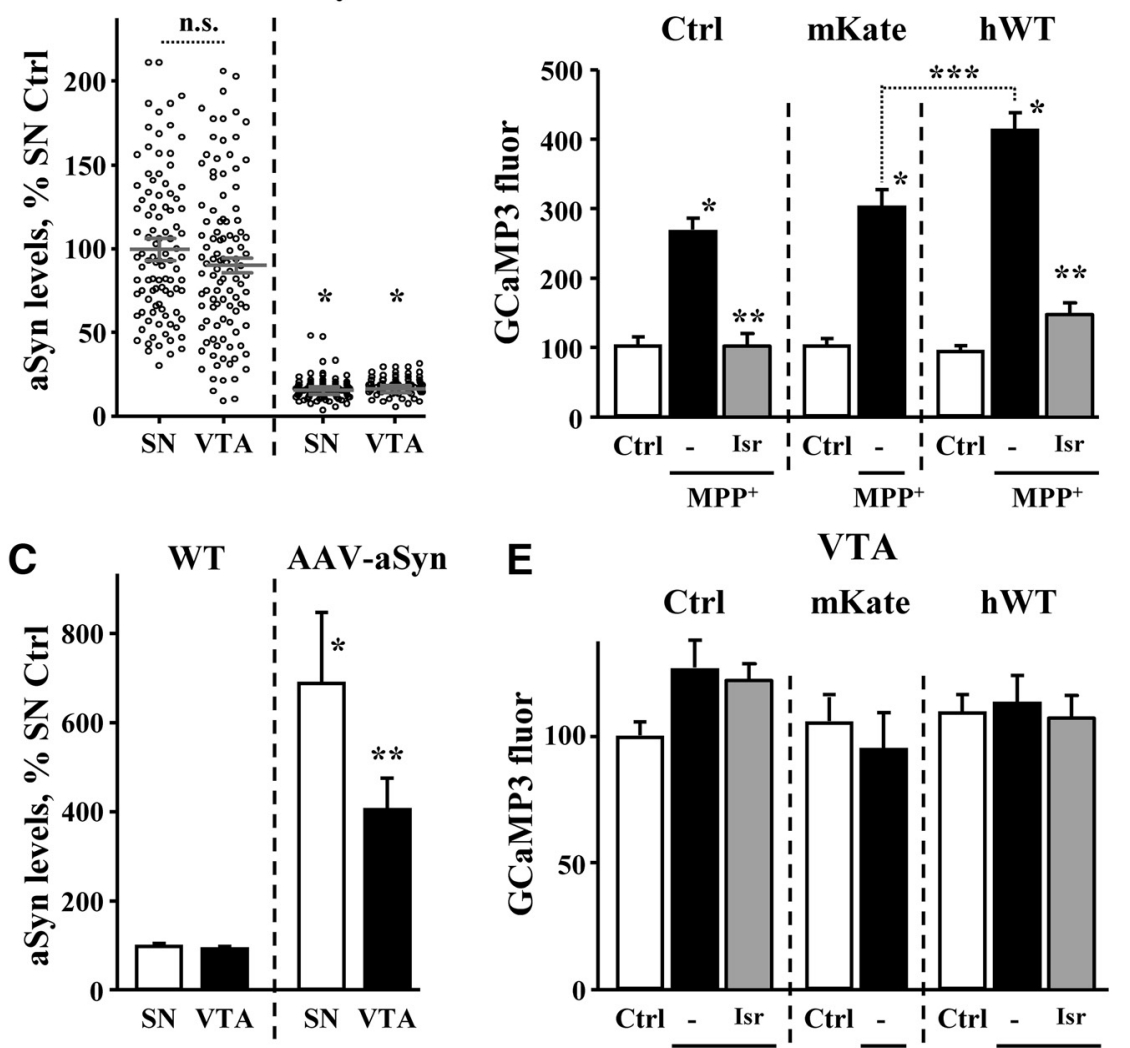

E
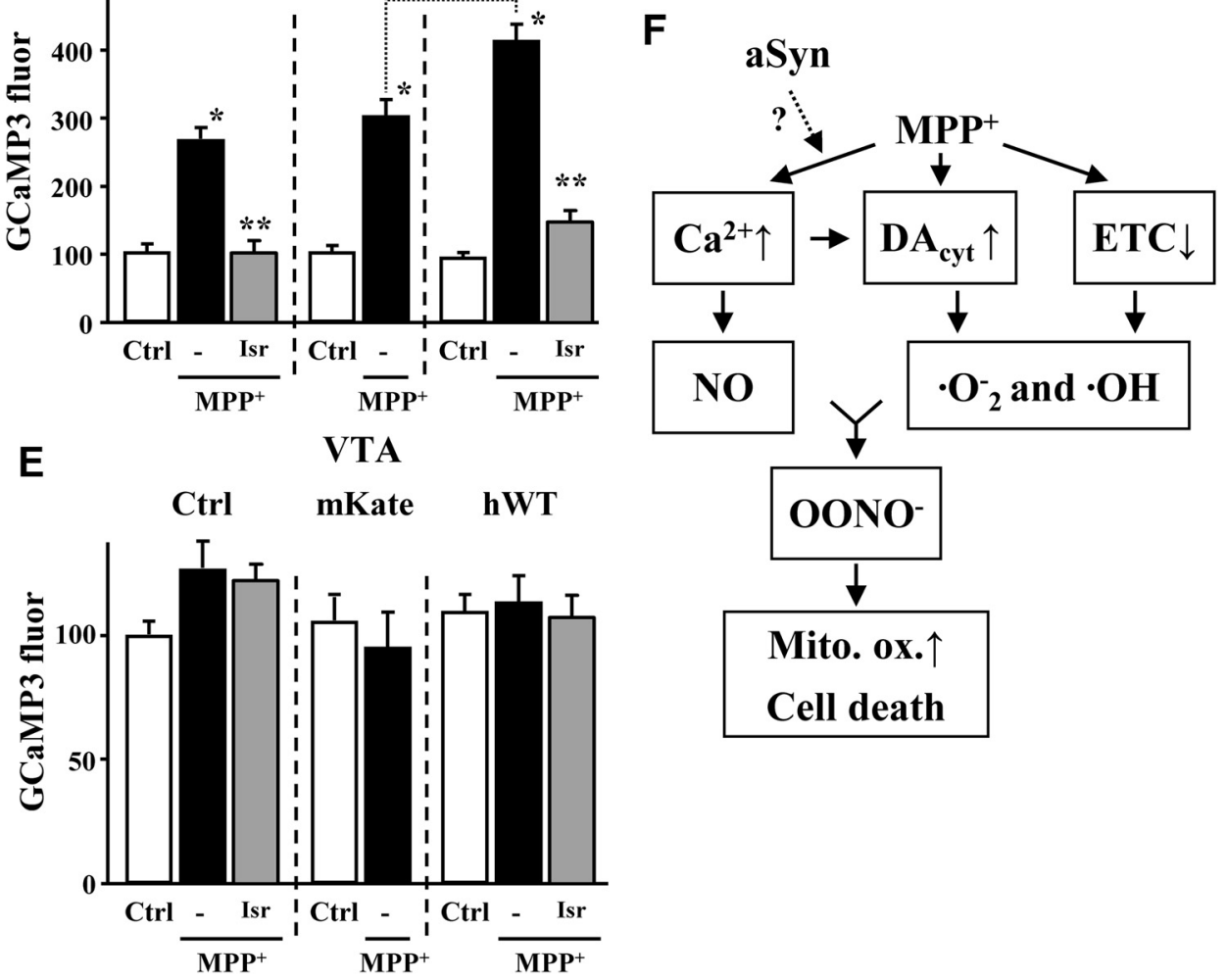

Figure 9. aSyn overexpression exacerbates the effect of $\mathrm{MPP}^{+}$on $\mathrm{Ca}^{2+}$ in SN but not VTA neurons. $\boldsymbol{A}$, Representative images of WT, aSyn KO, and aSyn-overexpressing SN neurons immuostained against TH and aSyn with antibodies that react with both mouse and human protein. To overexpress aSyn, cultures were infected with AAV2 carrying human WT aSyn under the control of CBA promoter. Immunostaining was done $5 \mathrm{~d}$ after the infection. Insets show the same images at different brightness range to allow seeing the pattern of exogenous aSyn expression. Scale bar: $10 \mu \mathrm{m}$. Note that nuclear staining that is present in both WT and AAV-aSyn neurons is absent in aSyn KO neuorns. $\boldsymbol{B}$, Quantification of endogenous cytosolic aSyn immunolabel in cultured SN and VTA DA neurons; * $p$ $<0.0001$ from WT SN and VTA neurons ( $n=83-127$ neurons from two independent experiments). $C$, Comparison of endogenous and 
continued

exogenous aSyn levels in SN and VTA neurons treated with AAV2-haSyn; $p<0.01$ from either WT (*) or both WT and SN AAV-aSyn groups (**) by one-way ANOVA with Tukey's post hoc test $(n=38-104$ cells from three independent experiments). $\boldsymbol{D}$, $\boldsymbol{E}$, Effect of human aSyn overexpression on cytosolic GCaMP3 fluorescence in SN $(\boldsymbol{D})$ and VTA $(\boldsymbol{E})$ DA neurons. One-week-old cultures of DAT-GCaMP3 neurons were infected with AAV2 carrying either mKate (red fluorescent tag) or human WT aSyn under the control of CBA promoter. GCaMP3 fluorescence in the presence and in the absence of MPP ${ }^{+}\left(50 \mu \mathrm{M} \mathrm{MPP}{ }^{+}\right.$for 2 h) was monitored $5 \mathrm{~d}$ after the infection; $p<0.001$ from corresponding control $(*)$, corresponding $\mathrm{MPP}^{+}(* *)$, or between indicated $\mathrm{MPP}^{+}$-treated groups $(* * *)$ by one-way ANOVA with Tukey's post hoc test ( $n=20-75$ cells for SN and 21-64 cells for VTA from four independent experiments). $\boldsymbol{F}$, Possible mechanism of neurotoxic interactions between $\mathrm{Ca}^{2+}, \mathrm{DA}_{\mathrm{cyt}}$, and $\mathrm{NO}$ in $\mathrm{MPP}^{+}$-treated $\mathrm{SN}$ neurons.

to produce DA still undergo MPTP-induced degeneration (Hasbani et al., 2005). Our data suggest that the contribution of DA toxicity can differ even between closely related cell types. While there was no significant effect of DA depletion in $\mathrm{MPP}^{+}$-treated VTA neurons, DA-related stress played a role in mitochondrial oxidation and accounted for a large portion of $\mathrm{MPP}^{+}$toxicity in SN neurons. Interestingly, LTCC basal activity, but not the MPP ${ }^{+}$ mediated increase in $\mathrm{Ca}^{2+}$, appears to underlie the different $\mathrm{DA}_{\text {cyt }}$ levels in SN and VTA neurons, as pharmacological or genetic blockade of the $\mathrm{Ca}_{\mathrm{v}} 1.3$ channels, but not of RyR, decreased $D_{\text {cyt }}$ in $\mathrm{SN}$ neurons, while the action of both channels was required for the toxininduced increase in $\mathrm{Ca}^{2+}$. We hypothesize that while LTCC increased basal DA synthesis in SN neurons (Mosharov et al., 2009), the main reason for elevated DA $A_{c y t}$ in $\mathrm{MPP}^{+}$-treated neurons was the inhibition of MAO by the toxin $\left(\mathrm{IC}_{50}=1 \mu \mathrm{M}\right.$; Choi et al., 2015).

Our results confirm that inhibition of NOS (Schulz et al., 1995; Hantraye et al., 1996; Przedborski et al., 1996) is effective at countering toxin-induced mitochondria oxidation. Specifically, $\mathrm{Ca}^{2+}$-mediated induction of mitochondrial nNOS (isoform $\alpha$; mtNOS; Traaseth et al., 2004; Marks et al., 2005) in SN neurons was responsible for their higher sensitivity to the toxin, as inhibition of mitochondrial $\mathrm{Ca}^{2+}$ uptake via MCU alleviated both the buildup of $\mathrm{NO}$ and toxicity in $\mathrm{MPP}^{+}$-treated cells. Similar upregulation of $\mathrm{Ca}^{2+} / \mathrm{NO}$ with concomitant mitochondria oxidative stress was recently demonstrated in LC catecholaminergic neurons (Sanchez-Padilla et al., 2014) and SN neurons exposed to aSyn preformed fibrils (Dryanovski et al., 2013), indicating that this pathway may be commonly activated under stress conditions.aSyn is the best established participant in the molecular pathology of PD, as mutations in the SNCA gene or its multiplication produce monogenic forms of PD (Eriksen et al., 2005). Moreover, genome wide association studies found a link between the SNCA locus and the risk of sporadic PD (International Parkinson Disease Genomics Consortium et al., 2011). Participation of this protein in PD is further supported by the presence of aSyn in Lewy bodies (Spillantini et al., 1997), its increased expression and phosphorylation in postmortem brains of sporadic PD patients (Fujiwara et al., 2002; Anderson et al., 2006; Murphy et al., 2014) and an autoimmune response to the protein in PD patients (Sulzer et al., 2017). While it has long been recognized that aSyn-deficient DA neurons show increased resistance to MPTP/MPP ${ }^{+}$toxicity (Dauer et al., 2002), the mechanism of neuroprotection remained elusive. Here, we demonstrate that in $\mathrm{MPP}^{+}$-treated $\mathrm{SN}$ neurons from aSyn $\mathrm{KO}$ mice, the pathologic surge of $\mathrm{Ca}^{2+}$ was not observed, preventing alterations in mitochondria morphology and cell death. In agreement with a recent study (Pathak et al., 2017), our data suggest that aSyn acts upstream of mitochondrial bioenergetics functions, most likely at the plasma membrane or ER where it modulates $\mathrm{Ca}^{2+}$ conductance. Interestingly, aSyn deletion was similar in effect to, and not additive with, the pharmacological blockade of LTCC that also nullified the differences between SN and VTA neurons and rescued SN neurons from $\mathrm{MPP}^{+}$toxicity. The involvement of these two established players of PD pathogenesis on the same toxicity pathway provides a foundation for further studies of the relationship between the activity of LTCC in cells susceptible in PD, aSyn pathology, and RyR-mediated depletion of ER $\mathrm{Ca}^{2+}$ stores that induces the unfolded protein response.

Overexpression of aSyn has been reported to increase MPTP/MPP+-mediated toxicity both in vitro and in vivo (Lee et al., 2001; Chung et al., 2005; Nieto et al., 2006; Zhou et al., 2006; Qian et al., 2008; Zhu et al., 2012). We found that the effect of aSyn varied between cell types. In $\mathrm{SN}$ neurons, excess of aSyn exacerbated the increase in $\mathrm{Ca}^{2+}$ caused by MPP ${ }^{+}$exposure, whereas in VTA neurons there was no detectable $\mathrm{Ca}^{2+}$ increase, regardless of aSyn expression levels (Fig. 9). These results demonstrate that (1) while aSyn expression is essential, it is not sufficient to elicit the $\mathrm{MPP}^{+}$-induced $\mathrm{Ca}^{2+}$ increase, which presumably required additional factors specifically expressed in SN neurons; (2) aSyn acts in concert with the LTCC; and (3) elevation of aSyn levels is insufficient to sensitize VTA neurons to MPP ${ }^{+}$.

Interestingly, while inhibitors of different toxicity pathways provided protection against $\mathrm{MPP}^{+}$, they were not more effective in combination. For example, isradipine and Bsrz each rescued SN neurons from $\mathrm{MPP}^{+}$-induced degeneration, but their effect was not additive (Figs. $2 B$, $7 G$ ). Similarly, L-NAME and succinate each decreased $\mathrm{MPP}^{+}$toxicity in isradipine-treated $\mathrm{SN}$ neurons, but the effect of both drugs applied simultaneously was the same as for each applied independently. Perhaps most surprisingly, the $\mathrm{MPP}^{+}$-induced oxidation of mitochondria was rescued with equal potency by isradipine, L-NAME, DHBP, RuR, and Bsrz, indicating that removing any of the stressors was sufficient to alleviate the toxicity (Fig. 7B). Thus, neurotoxicity may result from the synergistic interaction between several toxicity pathways in SN neurons. For example, generation of superoxide and hydroxyl radicals due to ETC inhibition and accumulation of DA ich, 1983; Fahn and Cohen, 1992) combined with $\mathrm{Ca}^{2+}$ mediated upregulation of NO synthesis may give rise to 
reactive nitrogen species, such as peroxynitrite (Przedborski et al., 1996; Pennathur et al., 1999; Fig. 9F). Alternatively, cellular redox defense systems might be overwhelmed when levels of $\mathrm{Ca}^{2+}, \mathrm{DA}_{\mathrm{cyt}}$, and $\mathrm{NO}$ increase simultaneously, but are able to cope with the stress when one of the metabolites' concentration is normalized; further work is required to distinguish between these and other possibilities. Several other questions still remain, including the reason for the difference in the time course of cell death in SN and VTA neurons, involvement of specific plasma membrane, ER and mitochondrial $\mathrm{Ca}^{2+}$ channels, and the effect of pathogenic mutant aSyn on $\mathrm{Ca}^{2+}$ homeostasis and toxicity in this toxicity model. Most importantly, the specifics of the mechanism by which $\mathrm{MPP}^{+}$induces $\mathrm{Ca}^{2+}$ surge in $\mathrm{SN}$ neurons needs further investigation.

Finally, we note that our results may have applicability beyond understanding the mechanisms of $\mathrm{MPP}^{+}$-induced cell death. Our findings with this parkinsonian neurotoxin, are mechanistically similar to a recent study of DA- and aSyn-mediated toxicity in human idiopathic and familial IPSC-derived DA neurons and of DJ-1 (PARK7) deficient mouse SN neurons in vivo (Burbulla et al., 2017). MPP $^{+}$ thus mimics several of the cardinal pathologic features of idiopathic and genetic PD, allowing us to unmask a novel interaction between aSyn, L-type calcium channels, and mitochondrial ROS which provides a blueprint through which genetic forms of PD caused by pathogenic aSyn may interface with sporadic forms related to elevated calcium burden and mitochondrial dysfunction. Our results buttress the hypothesis that selective degeneration of $\mathrm{SN}$ neurons in PD results from multiple genetic and neurotoxic "hits" that conspire to overwhelm cellular defense mechanisms (Sulzer, 2007; Mosharov et al., 2009).

\section{References}

Anderson JP, Walker DE, Goldstein JM, de Laat R, Banducci K, Caccavello RJ, Barbour R, Huang J, Kling K, Lee M, Diep L, Keim PS, Shen X, Chataway T, Schlossmacher MG, Seubert P, Schenk D, Sinha S, Gai WP, Chilcote TJ (2006) Phosphorylation of Ser-129 is the dominant pathological modification of $\alpha$-synuclein in familial and sporadic Lewy body disease. J Biol Chem 281:29739-29752. CrossRef

Avegno EM, Salling MC, Borgkvist A, Mrejeru A, Whitebirch AC, Margolis EB, Sulzer D, Harrison NL (2016) Voluntary adolescent drinking enhances excitation by low levels of alcohol in a subset of dopaminergic neurons in the ventral tegmental area. Neuropharmacology 110:386-395. CrossRef

Bäckman CM, Malik N, Zhang Y, Shan L, Grinberg A, Hoffer BJ, Westphal H, Tomac AC (2006) Characterization of a mouse strain expressing Cre recombinase from the 3' untranslated region of the dopamine transporter locus. Genesis 44:383-390. CrossRef

Branch SY, Sharma R, Beckstead MJ (2014) Aging decreases L-type calcium channel currents and pacemaker firing fidelity in substantia nigra dopamine neurons. J Neurosci 34:9310-9318. CrossRef

Burbulla LF, Song P, Mazzulli JR, Zampese E, Wong YC, Jeon S, Santos DP, Blanz J, Obermaier CD, Strojny C, Savas JN, Kiskinis E, Zhuang X, Krüger R, Surmeier DJ, Krainc D (2017) Dopamine oxidation mediates mitochondrial and lysosomal dysfunction in Parkinson's disease. Science 357:1255-1261. CrossRef

Caraveo G, Auluck PK, Whitesell L, Chung CY, Baru V, Mosharov EV, Yan X, Ben-Johny M, Soste M, Picotti P, Kim H, Caldwell KA, Caldwell GA, Sulzer D, Yue DT, Lindquist S (2014) Calcineurin determines toxic versus beneficial responses to $\alpha$-synuclein. Proc Natl Acad Sci USA 111:E3544-E3552. CrossRef
Chan CS, Guzman JN, Ilijic E, Mercer JN, Rick C, Tkatch T, Meredith GE, Surmeier DJ (2007) 'Rejuvenation' protects neurons in mouse models of Parkinson's disease. Nature 447:1081-1086. CrossRef Medline

Chavis P, Fagni L, Lansman JB, Bockaert J (1996) Functional coupling between ryanodine receptors and L-type calcium channels in neurons. Nature 382:719-722. CrossRef

Choi SJ, Panhelainen A, Schmitz Y, Larsen KE, Kanter E, Wu M, Sulzer D, Mosharov EV (2015) Changes in neuronal dopamine homeostasis following 1-methyl-4-phenylpyridinium (MPP+) exposure. J Biol Chem 290:6799-6809. CrossRef

Choi WS, Kruse SE, Palmiter RD, Xia Z (2008) Mitochondrial complex I inhibition is not required for dopaminergic neuron death induced by rotenone, MPP+, or paraquat. Proc Natl Acad Sci USA 105: 15136-15141. CrossRef Medline

Choi WS, Palmiter RD, Xia Z (2011) Loss of mitochondrial complex I activity potentiates dopamine neuron death induced by microtubule dysfunction in a Parkinson's disease model. J Cell Biol 192: 873-882. CrossRef

Chung CY, Seo H, Sonntag KC, Brooks A, Lin L, Isacson O (2005) Cell type-specific gene expression of midbrain dopaminergic neurons reveals molecules involved in their vulnerability and protection. Hum Mol Genet 14:1709-1725. CrossRef

Cui M, Aras R, Christian WV, Rappold PM, Hatwar M, Panza J, Jackson-Lewis V, Javitch JA, Ballatori N, Przedborski S, Tieu K (2009) The organic cation transporter-3 is a pivotal modulator of neurodegeneration in the nigrostriatal dopaminergic pathway. Proc Natl Acad Sci USA 106:8043-8048. CrossRef

Dagda RK, Cherra SJ 3rd, Kulich SM, Tandon A, Park D, Chu CT (2009) Loss of PINK1 function promotes mitophagy through effects on oxidative stress and mitochondrial fission. J Biol Chem 284:13843-13855. CrossRef

Dauer W, Kholodilov N, Vila M, Trillat AC, Goodchild R, Larsen KE, Staal R, Tieu K, Schmitz Y, Yuan CA, Rocha M, Jackson-Lewis V, Hersch S, Sulzer D, Przedborski S, Burke R, Hen R (2002) Resistance of $\alpha$-synuclein null mice to the parkinsonian neurotoxin MPTP. Proc Natl Acad Sci USA 99:14524-14529. CrossRef

Davis GC, Williams AC, Markey SP, Ebert MH, Caine ED, Reichert CM, Kopin IJ (1979) Chronic Parkinsonism secondary to intravenous injection of meperidine analogues. Psychiatry Res 1:249254. CrossRef

Dooley CT, Dore TM, Hanson GT, Jackson WC, Remington SJ, Tsien RY (2004) Imaging dynamic redox changes in mammalian cells with green fluorescent protein indicators. J Biol Chem 279:2228422293. CrossRef

Dryanovski DI, Guzman JN, Xie Z, Galteri DJ, Volpicelli-Daley LA, Lee VM, Miller RJ, Schumacker PT, Surmeier DJ (2013) Calcium entry and $\alpha$-synuclein inclusions elevate dendritic mitochondrial oxidant stress in dopaminergic neurons. J Neurosci 33:10154-10164.

Dufour MA, Woodhouse A, Amendola J, Goaillard JM (2014) Nonlinear developmental trajectory of electrical phenotype in rat substantia nigra pars compacta dopaminergic neurons. Elife 3. CrossRef

Eriksen JL, Przedborski S, Petrucelli L (2005) Gene dosage and pathogenesis of Parkinson's disease. Trends Mol Med 11:91-96. CrossRef Medline

Fahn S, Cohen G (1992) The oxidant stress hypothesis in Parkinson's disease: evidence supporting it. Ann Neurol 32:804-812. CrossRef Medline

Förstermann U, Schmidt HH, Pollock JS, Sheng H, Mitchell JA, Warner TD, Nakane M, Murad F (1991) Isoforms of nitric oxide synthase. Characterization and purification from different cell types. Biochem Pharmacol 42:1849-1857. CrossRef

Fridovich I (1983) Superoxide radical: an endogenous toxicant. Annu Rev Pharmacol Toxicol 23:239-257. CrossRef Medline

Fujiwara H, Hasegawa M, Dohmae N, Kawashima A, Masliah E, Goldberg MS, Shen J, Takio K, Iwatsubo T (2002) Alpha-synuclein is phosphorylated in synucleinopathy lesions. Nat Cell Biol 4:160164. 
González-Hernández T1, Barroso-Chinea P, De La Cruz Muros I, Del Mar Pérez-Delgado M, Rodríguez M (2004) Expression of dopamine and vesicular monoamine transporters and differential vulnerability of mesostriatal dopaminergic neurons. J Comp Neur 479:198-215. CrossRef

Guzman JN, Sanchez-Padilla J, Wokosin D, Kondapalli J, Ilijic E, Schumacker PT, Surmeier DJ (2010) Oxidant stress evoked by pacemaking in dopaminergic neurons is attenuated by DJ-1. Nature 468:696-700. CrossRef

Hajnóczky G, Robb-Gaspers LD, Seitz MB, Thomas AP (1995) Decoding of cytosolic calcium oscillations in the mitochondria. Cell 82:415-424. CrossRef

Hantraye P, Brouillet E, Ferrante R, Palfi S, Dolan R, Matthews RT, Beal MF (1996) Inhibition of neuronal nitric oxide synthase prevents MPTP-induced parkinsonism in baboons. Nat Med 2:10171021. CrossRef

Hasbani DM, Perez FA, Palmiter RD, O'Malley KL (2005) Dopamine depletion does not protect against acute 1-methyl-4-phenyl1,2,3,6-tetrahydropyridine toxicity in vivo. J Neurosci 25:94289433. CrossRef

Huitink GM, Poe DP, Diehl H (1974) On the properties of Calcein Blue. Talanta 21:1221-1229. Medline

Hurd YL, Pristupa ZB, Herman MM, Niznik HB, Kleinman JE (1994) The dopamine transporter and dopamine D2 receptor messenger RNAs are differentially expressed in limbic- and motor-related subpopulations of human mesencephalic neurons. Neuroscience 63:357-362. CrossRef

International Parkinson Disease Genomics Consortium, Nalls MA, Plagnol V, Hernandez DG, Sharma M, Sheerin UM, Saad M, Simón-Sánchez J, Schulte C, Lesage S, Sveinbjörnsdóttir S, Stefánsson K, Martinez M, Hardy J, Heutink P, Brice A, Gasser T, Singleton AB, Wood NW (2011) Imputation of sequence variants for identification of genetic risks for Parkinson's disease: a metaanalysis of genome-wide association studies. Lancet 377:641649. CrossRef

Jackson-Lewis V, Smeyne RJ (2005) MPTP and SNpc DA neuronal vulnerability: role of dopamine, superoxide and nitric oxide in neurotoxicity. Minireview. Neurotox Res 7:193-202. CrossRef

Javitch JA, D'Amato RJ, Strittmatter SM, Snyder SH (1985) Parkinsonism-inducing neurotoxin, N-methyl-4-phenyl-1,2,3,6 -tetrahydropyridine: uptake of the metabolite $\mathrm{N}$-methyl-4phenylpyridine by dopamine neurons explains selective toxicity. Proc Natl Acad Sci USA 82:2173-2177. CrossRef

Kakizawa S, Yamazawa T, Chen Y, Ito A, Murayama T, Oyamada H, Kurebayashi N, Sato O, Watanabe M, Mori N, Oguchi K, Sakurai T, Takeshima H, Saito N, lino M (2012) Nitric oxide-induced calcium release via ryanodine receptors regulates neuronal function. EMBO J 31:417-428. CrossRef

Karpowicz RJ Jr, Dunn M, Sulzer D, Sames D (2013) APP+, a fluorescent analogue of the neurotoxin MPP+, is a marker of catecholamine neurons in brain tissue, but not a fluorescent false neurotransmitter. ACS Chem Neurosci 4:858-869. CrossRef

Kim HW, Choi WS, Sorscher N, Park HJ, Tronche F, Palmiter RD, Xia Z (2015) Genetic reduction of mitochondrial complex I function does not lead to loss of dopamine neurons in vivo. Neurobiol Aging 36:2617-2627. CrossRef Medline

Kupsch A, Sautter J, Schwarz J, Riederer P, Gerlach M, Oertel WH (1996) 1-Methyl-4-phenyl-1,2,3,6-tetrahydropyridine-induced neurotoxicity in non-human primates is antagonized by pretreatment with nimodipine at the nigral, but not at the striatal level. Brain Res 741:185-196. CrossRef

Langston JW, Ballard P, Tetrud JW, Irwin I (1983) Chronic Parkinsonism in humans due to a product of meperidine-analog synthesis. Science 219:979-980. Medline

Lee M, Hyun D, Halliwell B, Jenner P (2001) Effect of the overexpression of wild-type or mutant alpha-synuclein on cell susceptibility to insult. J Neurochem 76:998-1009. Medline

Liss B, Haeckel O, Wildmann J, Miki T, Seino S, Roeper J (2005) K-ATP channels promote the differential degeneration of dopaminergic midbrain neurons. Nat Neurosci 8:1742-1751. CrossRef
Logan CV, Szabadkai G, Sharpe JA, Parry DA, Torelli S, Childs AM, Kriek M, Phadke R, Johnson CA, Roberts NY, Bonthron DT, Pysden KA, Whyte T, Munteanu I, Foley AR, Wheway G, Szymanska K, Natarajan S, Abdelhamed ZA, Morgan JE, et al. (2014) Loss-of-function mutations in MICU1 cause a brain and muscle disorder linked to primary alterations in mitochondrial calcium signaling. Nat Genet 46:188-193. CrossRef

Lotharius J, O'Malley KL (2000) The parkinsonism-inducing drug 1-methyl-4-phenylpyridinium triggers intracellular dopamine oxidation. A novel mechanism of toxicity. J Biol Chem 275:3858138588. CrossRef

Lotharius J, Dugan LL, O'Malley KL (1999) Distinct mechanisms underlie neurotoxin-mediated cell death in cultured dopaminergic neurons. J Neurosci 19:1284-1293.

Lüscher C, Slesinger PA (2010) Emerging roles for G protein-gated inwardly rectifying potassium (GIRK) channels in health and disease. Nat Rev Neurosci 11:301-315. CrossRef Medline

Marks JD, Boriboun C, Wang J (2005) Mitochondrial nitric oxide mediates decreased vulnerability of hippocampal neurons from immature animals to NMDA. J Neurosci 25:6561-6575. CrossRef

Maroteaux L, Campanelli JT, Scheller RH (1988) Synuclein: a neuronspecific protein localized to the nucleus and presynaptic nerve terminal. J Neurosci 8:2804-2815.

McCutcheon JE, Conrad KL, Carr SB, Ford KA, McGehee DS, Marinelli M (2012) Dopamine neurons in the ventral tegmental area fire faster in adolescent rats than in adults. J Neurophysiol 108: 1620-1630. CrossRef

Mercuri NB, Bonci A, Calabresi P, Stratta F, Stefani A, Bernardi G (1994) Effects of dihydropyridine calcium antagonists on rat midbrain dopaminergic neurones. $\mathrm{Br} J$ Pharmacol 113:831-838. CrossRef

Mosharov EV, Gong LW, Khanna B, Sulzer D, Lindau M (2003) Intracellular patch electrochemistry: regulation of cytosolic catecholamines in chromaffin cells. J Neurosci 23:5835-5845.

Mosharov EV, Larsen KE, Kanter E, Phillips KA, Wilson K, Schmitz Y, Krantz DE, Kobayashi K, Edwards RH, Sulzer D (2009) Interplay between cytosolic dopamine, calcium, and $\alpha$-synuclein causes selective death of substantia nigra neurons. Neuron 62:218-229. CrossRef

Murphy KE, Gysbers AM, Abbott SK, Tayebi N, Kim WS, Sidransky E, Cooper A, Garner B, Halliday GM (2014) Reduced glucocerebrosidase is associated with increased $\alpha$-synuclein in sporadic Parkinson's disease. Brain 137:834-848. CrossRef

Nieto M, Gil-Bea FJ, Dalfó E, Cuadrado M, Cabodevilla F, Sánchez B, Catena S, Sesma T, Ribé E, Ferrer I, Ramírez MJ, Gómez-Isla T (2006) Increased sensitivity to MPTP in human $\alpha$-synuclein A30P transgenic mice. Neurobiol Aging 27:848-856. CrossRef

Pacelli C, Giguère N, Bourque MJ, Lévesque M, Slack RS, Trudeau LÉ (2015) Elevated mitochondrial bioenergetics and axonal arborization size are key contributors to the vulnerability of dopamine neurons. Curr Biol 25:2349-2360. CrossRef

Pathak D, Berthet A, Bendor JT, Yu K, Sellnow RC, Orr AL, Nguyen MK, Edwards RH, Manfredsson FP, Nakamura K (2017) Loss of $\alpha$-synuclein does not affect mitochondrial bioenergetics in rodent neurons. eNeuro 4. CrossRef

Patron M, Checchetto V, Raffaello A, Teardo E, Vecellio Reane D, Mantoan M, Granatiero V, Szabò I, De Stefani D, Rizzuto R (2014) MICU1 and MICU2 finely tune the mitochondrial Ca2 + uniporter by exerting opposite effects on MCU activity. Mol Cell 53:726737. CrossRef

Pennathur S, Jackson-Lewis V, Przedborski S, Heinecke JW (1999) Mass spectrometric quantification of 3-nitrotyrosine, orthotyrosine, and o,o'-dityrosine in brain tissue of 1-methyl-4-phenyl1,2,3, 6-tetrahydropyridine-treated mice, a model of oxidative stress in Parkinson's disease. J Biol Chem 274:34621-34628. CrossRef

Przedborski S, Jackson-Lewis V, Yokoyama R, Shibata T, Dawson VL, Dawson TM (1996) Role of neuronal nitric oxide in 1-methyl4-phenyl-1,2,3,6-tetrahydropyridine (MPTP)-induced dopaminer- 
gic neurotoxicity. Proc Natl Acad Sci USA 93:4565-4571. CrossRef

Qian JJ, Cheng YB, Yang YP, Mao CJ, Qin ZH, Li K, Liu CF (2008) Differential effects of overexpression of wild-type and mutant human $\alpha$-synuclein on MPP+-induced neurotoxicity in PC12 cells. Neurosci Lett 435:142-146. CrossRef

Rayport S, Sulzer D, Shi WX, Sawasdikosol S, Monaco J, Batson D, Rajendran G (1992) Identified postnatal mesolimbic dopamine neurons in culture: morphology and electrophysiology. J Neurosci $12: 4264-4280$.

Roeper J (2013) Dissecting the diversity of midbrain dopamine neurons. Trends Neurosci 36:336-342. CrossRef Medline

Ryan BJ, Hoek S, Fon EA, Wade-Martins R (2015) Mitochondrial dysfunction and mitophagy in Parkinson's: from familial to sporadic disease. Trends Biochem Sci 40:200-210. CrossRef

Sanchez-Padilla J, Guzman JN, Ilijic E, Kondapalli J, Galtieri DJ, Yang B, Schieber S, Oertel W, Wokosin D, Schumacker PT, Surmeier DJ (2014) Mitochondrial oxidant stress in locus coeruleus is regulated by activity and nitric oxide synthase. Nat Neurosci 17: 832-840. CrossRef

Sanghera MK, Manaye K, McMahon A, Sonsalla PK, German DC (1997) Dopamine transporter mRNA levels are high in midbrain neurons vulnerable to MPTP. Neuroreport 8:3327-3331. CrossRef

Sawamoto K, Nakao N, Kobayashi K, Matsushita N, Takahashi H, Kakishita K, Yamamoto A, Yoshizaki T, Terashima T, Murakami F, Itakura T, Okano H (2001) Visualization, direct isolation, and transplantation of midbrain dopaminergic neurons. Proc Natl Acad Sci USA 98:6423-6428. CrossRef

Schulz JB, Matthews RT, Muqit MM, Browne SE, Beal MF (1995) Inhibition of neuronal nitric oxide synthase by 7-nitroindazole protects against MPTP-induced neurotoxicity in mice. J Neurochem 64:936-939. CrossRef

Shcherbo D, Murphy CS, Ermakova GV, Solovieva EA, Chepurnykh TV, Shcheglov AS, Verkhusha VV, Pletnev VZ, Hazelwood KL, Roche PM, Lukyanov S, Zaraisky AG, Davidson MW, Chudakov DM (2009) Far-red fluorescent tags for protein imaging in living tissues. Biochem J 418:567-574. CrossRef

Shimada S, Kitayama S, Walther D, Uhl G (1992) Dopamine transporter mRNA: dense expression in ventral midbrain neurons. Brain Res Mol Brain Res 13:359-362. CrossRef

Spillantini MG, Schmidt ML, Lee VM, Trojanowski JQ, Jakes R, Goedert M (1997) Alpha-synuclein in Lewy bodies. Nature 388: 839-840. CrossRef Medline

Sulzer D (2007) Multiple hit hypotheses for dopamine neuron loss in Parkinson's disease. Trends Neurosci 30:244-250. CrossRef Medline

Sulzer D, Alcalay RN, Garretti F, Cote L, Kanter E, Agin-Liebes J, Liong C, McMurtrey C, Hildebrand WH, Mao X, Dawson VL, Dawson TM, Oseroff C, Pham J, Sidney J, Dillon MB, Carpenter C,
Weiskopf D, Phillips E, Mallal S, et al. (2017) T cells from patients with Parkinson's disease recognize $\alpha$-synuclein peptides. Nature 546:656-661. CrossRef

Surmeier DJ (2007) Calcium, ageing, and neuronal vulnerability in Parkinson's disease. Lancet Neurol 6:933-938. CrossRef Medline

Takeuchi K, Sato SI, Abe K, Kimura M, Abe TA, Yoshinaga K, Inaba H (1989) Intracellular compartmentalization of fura-2 dye demonstrated by laser-excitation fluorescence microscopy: a problem in measuring cytosolic free calcium concentration using fura-2 fluorescence in vascular smooth muscle cells. Tohoku J Exp Med 159:23-35. CrossRef

Tateno T, Robinson HP (2011) The mechanism of ethanol action on midbrain dopaminergic neuron firing: a dynamic-clamp study of the role of I(h) and GABAergic synaptic integration. J Neurophysiol 106:1901-1922. CrossRef

Tian L, Hires SA, Mao T, Huber D, Chiappe ME, Chalasani SH, Petreanu L, Akerboom J, McKinney SA, Schreiter ER, Bargmann Cl, Jayaraman V, Svoboda K, Looger LL (2009) Imaging neural activity in worms, flies and mice with improved GCaMP calcium indicators. Nat Methods 6:875-881. CrossRef

Traaseth N, Elfering S, Solien J, Haynes V, Giulivi C (2004) Role of calcium signaling in the activation of mitochondrial nitric oxide synthase and citric acid cycle. Biochim Biophys Acta 1658:64-71. CrossRef

Wang X, Su B, Liu W, He X, Gao Y, Castellani RJ, Perry G, Smith MA, Zhu X (2011) DLP1-dependent mitochondrial fragmentation mediates 1-methyl-4-phenylpyridinium toxicity in neurons: implications for Parkinson's disease. Aging Cell 10:807-823. CrossRef

Yee AG, Lee SM, Hunter MR, Glass M, Freestone PS, Lipski J (2014) Effects of the Parkinsonian toxin MPP+ on electrophysiological properties of nigral dopaminergic neurons. Neurotoxicology 45:111. CrossRef

Yodoya E, Wada M, Shimada A, Katsukawa H, Okada N, Yamamoto A, Ganapathy V, Fujita T (2006) Functional and molecular identification of sodium-coupled dicarboxylate transporters in rat primary cultured cerebrocortical astrocytes and neurons. J Neurochem 97:162-173. CrossRef

Zariwala HA, Borghuis BG, Hoogland TM, Madisen L, Tian L, De Zeeuw Cl, Zeng H, Looger LL, Svoboda K, Chen TW (2012) A Cre-dependent GCaMP3 reporter mouse for neuronal imaging in vivo. J Neurosci 32:3131-3141. CrossRef

Zhou ZD, Yap BP, Gung AY, Leong SM, Ang ST, Lim TM (2006) Dopamine-related and caspase-independent apoptosis in dopaminergic neurons induced by overexpression of human wild type or mutant alpha-synuclein. Exp Cell Res 312:156-170. CrossRef Medline

Zhu M, Li W, Lu C (2012) Role of alpha-synuclein protein levels in mitochondrial morphology and cell survival in cell lines. PLoS One 7:e36377. CrossRef Medline 